\title{
Tuning the cell uptake and subcellular distribution in BODIPY- carboranyl dyads: An experimental and theoretical study.
}

\begin{abstract}
Pablo Labra-Vázquez, ${ }^{\text {a,d }}$ Ricardo Flores-Cruz, ${ }^{\text {b }}$ Aylin Galindo-Hernández, ${ }^{\text {a }}$ Justo Cabrera-González, ${ }^{c}$ Cristian Guzmán-Cedillo, ${ }^{a}$ Arturo Jiménez-Sánchez, ${ }^{b}$ Pascal G.
\end{abstract} Lacroix, ${ }^{\mathrm{d}}$ Rosa Santillan, ${ }^{\mathrm{e}}$ Norberto Farfán, ${ }^{*, a}$ and Rosario Núñez ${ }^{*, c}$

a Facultad de Química, Departamento de Química Orgánica, Universidad Nacional Autónoma de México, 04510 Ciudad de México, México.

b Instituto de Química, Universidad Nacional Autónoma de México, 04510 Ciudad de México, México.

${ }^{\mathbf{c}}$ Institut de Ciència de Materials de Barcelona (ICMAB-CSIC), Campus de la UAB, E-08193 Bellaterra, Barcelona, Spain.

d Laboratoire de Chimie de Coordination du CNRS, 205 route de Narbonne, F-31077, Toulouse, France.

e Departamento de Química, Centro de Investigación y de Estudios Avanzados del IPN, Apdo. Postal 14-740, 07000, Ciudad de México, México. 


\section{For Table-of-Contents use only.}

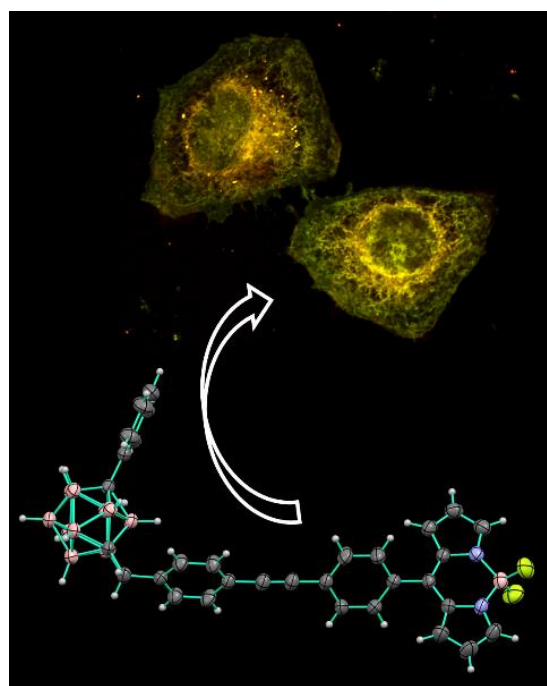

meta-

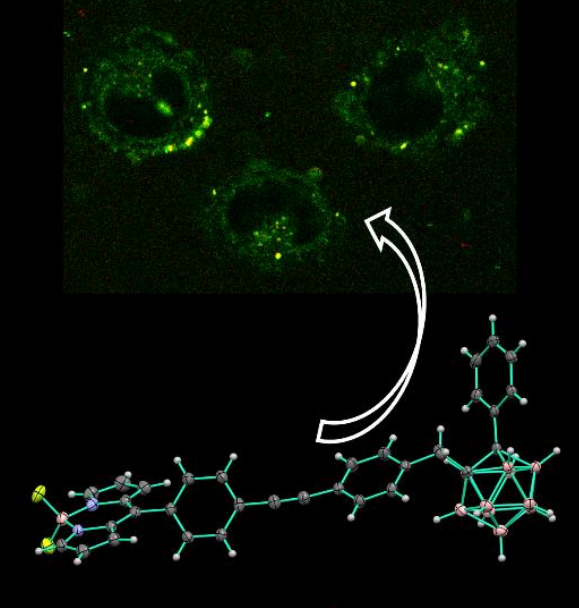

ortho-

Round 1! Fluorophores bearing carborane clusters often display remarkably different cell incomes, with recurrent higher permeabilities for meta-carboranes compared to orthoisomers. Here, we study a set of BODIPY-carborane dyads to provide an explanation for these differences, which originate from important variations in their partition coefficients and static dipole moments. 


\section{ABSTRACT}

A set of BODIPY-carboranyl dyads synthesized by a Sonogashira cross-coupling reaction, where different C-substituted ortho- and meta-carboranyl fragments have been linked to a BODIPY fluorophore is described. Chemical, photophysical and physicochemical analyses are presented, including NMR and SXRD experiments, optical absorption/emission studies and $\log P$ measurements. These studies, supported by DFT computations (M06-2X/6-31G**) provide an explanation to the largely divergent cell income that these fluorescent carboranylbased fluorophores display, for which a structural or physicochemical explanation remains

elusive. By studying the cell uptake efficiency and subcellular localization for our set of dyads on living HeLa cells, we tracked the origins of these differences to significant variations in their static dipole moments and partition coefficients, which tune their ability to interact with lipophilic microenvironments in cells. Remarkably, $m$-carboranyl-BODIPY derivatives with a higher lipophilicity are much better internalised by cells than their homologous with $o$-carborane, suggesting that $m$-isomers are potentially better theranostic agents for in vitro bioimaging and boron carriers for BNCT. 


\section{INTRODUCTION}

Dicarba-closo-dodecaboranes (icosahedral 12-vertex species usually named carboranes, $\mathrm{C}_{2} \mathrm{~B}_{10} \mathrm{H}_{12}$ ) are chemically intriguing boron clusters bearing two endocyclic carbon atoms. ${ }^{[1]}$ They possess remarkable chemical, thermal and photochemical stabilities, ${ }^{[2]}$ and spherical aromaticity through $\sigma$-delocalized electron densities, owed to the ubiquitous occurrence of multicentered bonds within their skeletons. ${ }^{[3]}$ Consequently, these boranes display some electronic properties and sizes similar to those of a rotating benzene ring ${ }^{[4]}$ and, accordingly, isomers $1,2-1,7$ - and 1,12-closo- $\mathrm{C}_{2} \mathrm{~B}_{10} \mathrm{H}_{12}$ are typically named ortho-, meta- and paracarboranes, respectively. In this sense, it has been demonstrated that the different electronic properties of carborane isomers can notably change the photophysical behaviour of fluorophores linked through a carbon cluster atom $\left(\mathrm{C}_{\mathrm{c}}\right) .{ }^{[2 a, 5]}$ Their unique characteristics have given carborane derivatives increasing research interest during the last decade in diverse fields, including catalysis, ${ }^{[6]}$ optoelectronics ${ }^{[7]}$ nonlinear optics,${ }^{[8]}$ and materials science, ${ }^{[9]}$ particularly in the preparation of highly thermally stable polymers. ${ }^{[2 c]}$ Moreover, carboranes show low toxicity and high stability in biological systems, ${ }^{[10]}$ and their hydrophobic nature has proved to enhance the diffusion across the cellular membranes of carborane-bearing drugs. ${ }^{[11]}$ Owing to these features, one of the largest field of study covers the potential of carborane-based molecules in biomedical applications, in especial as candidates to be used as agents for boron neutron capture therapy (BNCT). ${ }^{[4 b, 12]}$ This anti-cancer therapy relies on the controlled cell death due to ionizing radiation released from ${ }^{10} \mathrm{~B}$ nuclei after irradiation with thermal neutrons. ${ }^{[13]}$

Currently, one of the most outstanding areas of development is the design of new fluorophores as efficient in vitro imaging probes to be applied in optical imaging. The 
integration of one imaging agent with a target drug in a single system leads to the development of a theranostic agent, allowing simultaneously diagnosis and treatment of a specific disease. Nevertheless, relevant structure-related properties such as subcellular biodistribution and dynamic of fluorescent-derived carboranes are still an unmet need. To move towards this goal, several chemical architectures containing carborane fragments have been synthetized by our group, ${ }^{[14]}$ however their molecular structures cannot be easily related to their subcellular distribution and function, even though some correlation of general physicochemical observables has been reported to be helpful on achieving specific biological properties for a great variety of compounds. ${ }^{[1 \mathrm{~b}, 10 \mathrm{~d}, 15]}$

Among the wide family of fluorophores addressed to bioimaging and chemosensing, BODIPY (4,4-difluoro-4-bora-3a,4a-diaza-s-indacene) dyes have found an increased interest due to their unique spectroscopic properties, ${ }^{[16]}$ synthetic versatility, ${ }^{[17]}$ low toxicity and good stability under physiological conditions. ${ }^{[18]}$ Furthermore, synthesis of BODIPYs bearing carborane $^{[19]}$ and metallacarborane clusters ${ }^{[20]}$ have been reported and their photophysical properties assessed. Although some of the studied BODIPY-carboranyl dyads have displayed exceptional cellular uptake toward HeLa cells, making these clusters good candidates for in vitro cell tracking, it is often encountered that small changes in the molecular structure deeply modify their cellular internalization ability. ${ }^{[19 f, g]}$

There exists a consistent evidence suggesting that cell permeability towards carboranebased compounds is directly influenced by the lipophilic character of the compounds, ${ }^{[21]}$ which depends on the partition coefficient that in turn is modulated by the dipole moment and the van der Waals volume of the molecule. ${ }^{[2]}$ According to this, we decided to investigate a new set of BODIPY-carboranyl dyads specifically intended to correlate these 
structural parameters, not only with their cellular uptake efficiency but also with their subcellular distribution features.

The target compounds are shown in Chart 1. BODIPY-o-Me-CB and BODIPY-o-Ph-CB have disubstituted ortho-carborane cages, where the difference substituents linked to the adjacent $\mathrm{C}_{\mathrm{c}}$ (methyl and phenyl) is expected to yield a significant change in the van der Waals volume, while the dipole moment should be similar. Conversely, when comparing BODIPY$\boldsymbol{o}-\mathbf{P h}-\mathbf{C B}$ with BODIPY-m-Ph-CB, the van der Waals volume is expected to be relatively unaltered, whereas there should be a significant change in the static dipole moments between both isomers, in agreement with previous reports on the chemistry of carboranes. ${ }^{[1 \mathrm{~b}]}$ Thus, these comparisons would allow us to stablish separately the influence of these structural features on the cellular uptake efficiency. Finally, BODIPY-Ref, having no carborane fragment, was included as a reference compound to evaluate how the insertion of different C-substituted $o$ - and $m$-carboranyl units into the BODIPY fluorophore influence the cellular uptake and biodistribution.
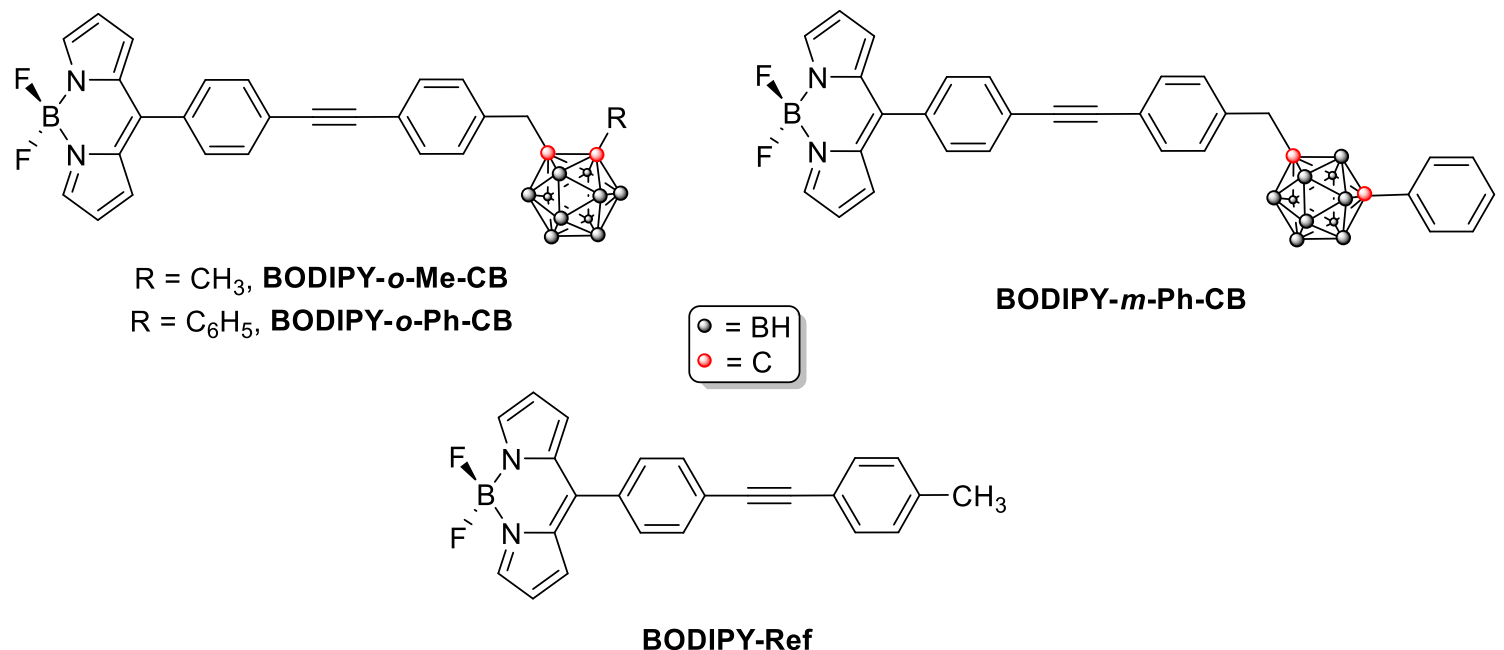

Chart 1. BODIPY derivatives under investigation. 


\section{RESULTS AND DISCUSSION}

\section{Synthesis and Characterization}

The synthesis of the target compounds (Scheme 1) was carried out employing a Sonogashira cross-coupling reaction as the key synthetic step from BODIPY 1, which was coupled to 4iodotoluene and the carboranyl derivatives $\boldsymbol{o}$-Me-CB, $\boldsymbol{o}-\mathbf{P h}-\mathbf{C B}$ and $\boldsymbol{m}$-Ph-CB (further synthetic details are gathered in the SI), ${ }^{[5]}$ to produce the fluorophores in moderate to good yields. The identity of these compounds was stablished using multinuclear ${ }^{1} \mathrm{H},{ }^{13} \mathrm{C}\left\{{ }^{1} \mathrm{H}\right\},{ }^{11} \mathrm{~B}$ and ${ }^{19}$ F-NMR and HRMS and SXRD experiments (Details are gathered in the Supporting Information).

The unambiguous assignment of the ${ }^{1} \mathrm{H}$ and ${ }^{13} \mathrm{C}\left\{{ }^{1} \mathrm{H}\right\}$ signals for the target compounds was carried out with the help of homonuclear ${ }^{1} \mathrm{H}-{ }^{1} \mathrm{H}(\mathrm{COSY}, \mathrm{NOESY})$ and heteronuclear ${ }^{1} \mathrm{H}-{ }^{13} \mathrm{C}$ (HSQC/HMBC) 2D-NMR experiments. Signals from the B-H protons of the clusters appeared as broad multiplets, from $\delta=1.74$ to $2.96 \mathrm{ppm}$, due to the ubiquitous ${ }^{1} \mathrm{H}_{-}{ }^{11} \mathrm{~B}$ and ${ }^{1} \mathrm{H}-{ }^{10} \mathrm{~B}$ scalar couplings. Aliphatic protons from the methylene (H-16) in the carboranyl fluorophores appeared in the $\delta=3.12$ - 3.49 ppm interval; resonating at higher frequencies when compared to the protons of the methyl group in BODIPY-Ref $(\mathrm{H}-16)$ with $\delta=2.39$ ppm. This observation is in good agreement with the broadly recognized inductive electronwithdrawing nature of boranes, ${ }^{[23]}$ here providing a rationale to the iterative deshielding of these nuclei. Although this influence further echoes strongly on the resonance of C-16, with $\delta=21.55 \mathrm{ppm}$ for BODIPY-Ref and $\delta=40.78-43.01 \mathrm{ppm}$ for the carboranyl derivatives, the chemical shifts for the aromatic nuclei of the 4 fluorophores were seemingly unaffected, suggesting a localized withdrawing effect and a rather low electronic coupling between the carboranyl and BODIPY cores. This result matches well with the optical spectra and the DFT 
computations for these compounds (vide infra), which confirmed the lack of electronic communication between the two sub-molecular fragments. ${ }^{11} \mathrm{~B}$ NMR spectra also confirmed the formation of the expected compounds showing for all of them similar patterns, with one resonance at $-0.60 \mathrm{ppm}$ assigned to the $\mathrm{BF}_{2}$ group and broad resonances in the range from $\delta$ -6 to -15 ppm characteristic from closo-carborane clusters.

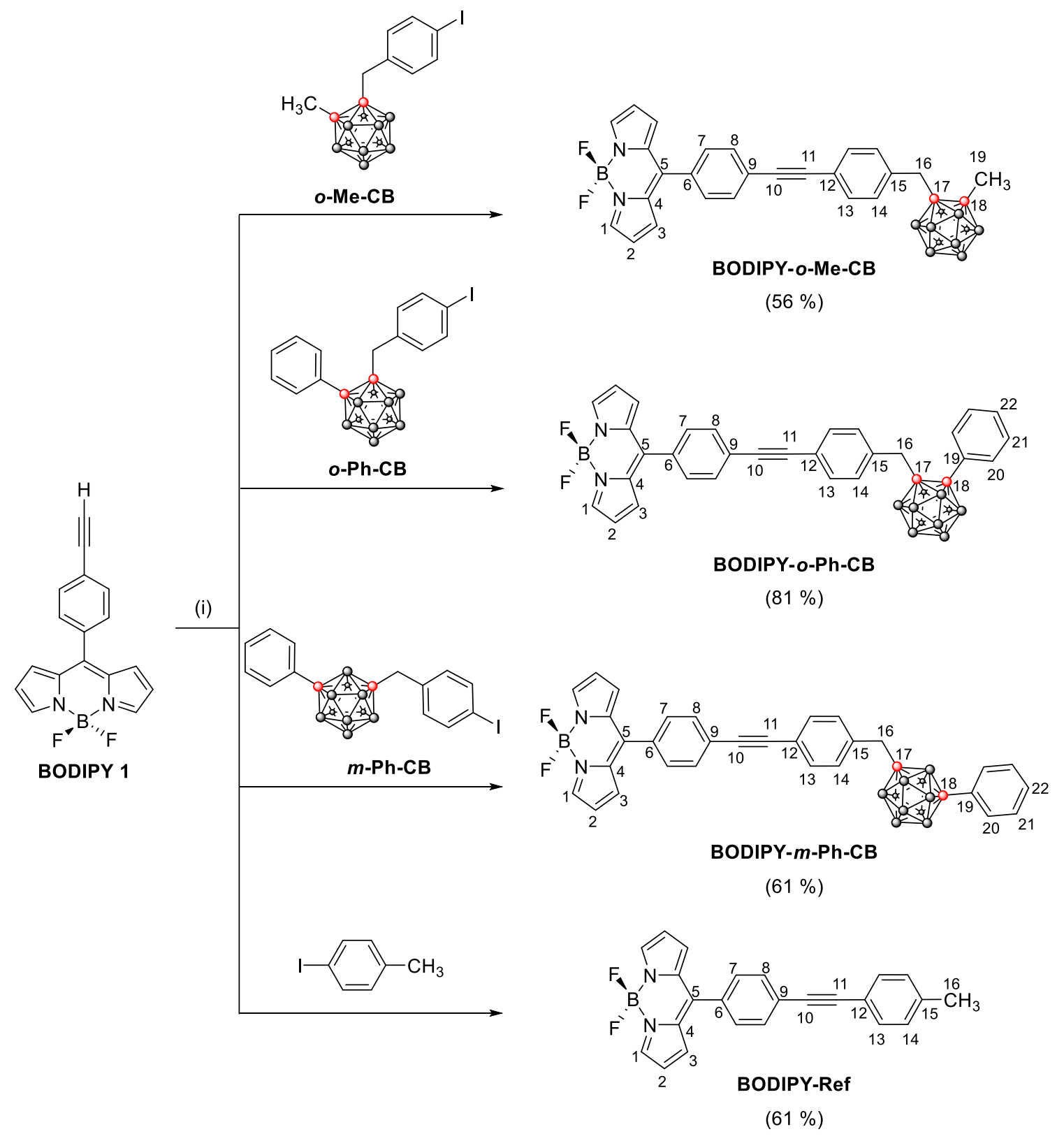

Scheme 1. Synthesis and numbering for the target BODIPY derivatives. Reagents and general conditions: (i) $\mathrm{Pd}\left(\mathrm{PPh}_{3}\right)_{2} \mathrm{Cl}_{2}, \mathrm{CuI}, \mathrm{THF}, \mathrm{Et}_{3} \mathrm{~N}$, reflux. 


\section{X-Ray Diffraction Studies}

Crystals of $\boldsymbol{m}$-Ph-CB and all of the target BODIPY derivatives suitable for single-crystal Xray diffraction analysis were grown by room temperature evaporation of their saturated solutions in acetone $/ n$-hexane mixtures. Excepting BODIPY-Ref, which crystallized with a single fluorophore molecule per asymmetric unit $\left(Z^{\prime}=1\right)$, all the other BODIPY derivatives crystallized with $Z^{\prime}=2$. In the BODIPY-o-Me-CB, the asymmetric unit is composed by two fluorophore molecules crystallographically independent yet geometrically close. BODIPY$\boldsymbol{o}$-Ph-CB and BODIPY- $\boldsymbol{m}$-Ph-CB crystallized with one molecule of the fluorophore and half of a disordered $n$-hexane coming from the crystallization process. Figures 1-2 show the molecular structures for these compounds including relevant distances and angles (further crystallographic details are gathered in Table 1). No significant differences in bond lengths and angles were found for $\boldsymbol{m}$-Ph-CB when compared to the previously reported crystal structure of its ortho- isomer, $\boldsymbol{o}-\mathbf{P h}-\mathbf{C B}{ }^{[5]}$ The introduction of the BODIPY fluorophore did not alter significantly the bond lengths related to the dicarbaborane cluster as compared with $\boldsymbol{m}$-Ph-CB. Indeed, bond lengths among the annular $\mathrm{C}_{\mathrm{c}}$ atoms $(\mathrm{C} 8-\mathrm{C} 9$ for $\boldsymbol{m}-\mathbf{P h}-\mathbf{C B}$, otherwise $\mathrm{C} 25-\mathrm{C} 26)$ and the $\mathrm{C}$ atoms directly attached to them remained unchanged, even though the BODIPY core is a strong withdrawing group owed to the delocalized positive charge within its tricyclic framework. This observation is in good agreement with the lack of electronic coupling between the carboranyl and BODIPY sub-molecular fragments as evidenced by the NMR and DFT studies (vide infra). Furthermore, the delocalization within the BODIPY core is further evidenced by the almost equal N1-B1/N2-B1 distances and N1B1-F1/N2-B1-F2 angles, depicting similar bond strengths among these atoms. 
Table 1. Crystal Structure and Refinement Data

\begin{tabular}{|c|c|c|c|c|c|}
\hline & $m-\mathrm{Ph}-\mathrm{CB}$ & BODIPY-o-Me-CB & BODIPY-o-Ph-CB & BODIPY-m-Ph-CB & BODIPY-Ref \\
\hline empirical formula & $\mathrm{C}_{15} \mathrm{H}_{21} \mathrm{~B}_{10} \mathrm{I}$ & $\mathrm{C}_{27} \mathrm{H}_{29} \mathrm{~B}_{11} \mathrm{~F}_{2} \mathrm{~N}_{2}$ & $\begin{array}{l}\mathrm{C}_{32} \mathrm{H}_{31} \mathrm{~B}_{11} \mathrm{~F}_{2} \mathrm{~N}_{2} \\
0.5\left(\mathrm{C}_{6} \mathrm{H}_{14}\right)\end{array}$ & $\begin{array}{l}\mathrm{C}_{32} \mathrm{H}_{31} \mathrm{~B}_{11} \mathrm{~F}_{2} \mathrm{~N}_{2}, \\
0.5\left(\mathrm{C}_{6} \mathrm{H}_{14}\right)\end{array}$ & $\mathrm{C}_{24} \mathrm{H}_{17} \mathrm{BF}_{2} \mathrm{~N}_{2}$ \\
\hline temperature $(\mathrm{K})$ & $130(2)$ & $299(2)$ & 293(2) & $297(2)$ & $294(2)$ \\
\hline crystal system & Orthorhombic & Monoclinic & Triclinic & Triclinic & Triclinic \\
\hline space group & $P 2{ }_{1} 2_{1} 2_{1}$ & $P 2{ }_{1} / \mathrm{n}$ & $P-1$ & $P-1$ & $P-1$ \\
\hline$a(\AA)$ & $7.7896(3)$ & $14.8970(7)$ & $8.2770(4)$ & $10.6616(7)$ & $7.6541(5)$ \\
\hline $\mathrm{b}(\AA)$ & $11.6611(5)$ & $15.5300(7)$ & $11.8101(8)$ & $12.0496(8)$ & $7.8995(5)$ \\
\hline c $(\AA)$ & $20.9589(9)$ & $26.5342(11)$ & $18.2600(10)$ & $13.4696(8)$ & $16.6764(11)$ \\
\hline$\alpha(\mathrm{deg})$ & 90 & 90 & $86.936(5)$ & $89.052(2)$ & $100.375(2)$ \\
\hline$\beta(\mathrm{deg})$ & 90 & $103.5900(10)$ & $80.300(4)$ & $89.018(2)$ & $97.336(2)$ \\
\hline$\gamma(\mathrm{deg})$ & 90 & 90 & $79.934(5)$ & $88.341(2)$ & $103.098(2)$ \\
\hline volume $(\AA)^{3}$ & $1903.81(14)$ & $5966.8(5)$ & $1731.82(18)$ & 1729.21(19) & $950.97(11)$ \\
\hline$Z$ & 4 & 8 & 2 & 2 & 2 \\
\hline $\begin{array}{l}\text { density } \\
\left(\mathrm{g} \cdot \mathrm{cm}^{-3}\right)\end{array}$ & 1.522 & 1.199 & 1.218 & 1.236 & 1.335 \\
\hline $\begin{array}{l}\text { Crystal } \\
\text { size }(\mathrm{mm})\end{array}$ & $0.41 \times 0.36 \times 0.32$ & $0.40 \times 0.32 \times 0.19$ & $0.45 \times 0.26 \times 0.12$ & $0.25 \times 0.25 \times 0.12$ & $0.52 \times 0.39 \times 0.26$ \\
\hline$\theta$ range $(\mathrm{deg})$ & $3.89-29.94$ & $2.20-26.45$ & $3.51-30.00$ & $2.25-23.27$ & $2.52-30.13$ \\
\hline reflns collected/unique & $7955 / 4458$ & $190178 / 11516$ & $17155 / 6305$ & $32185 / 4577$ & $78656 / 5606$ \\
\hline final $R$ indices & $\mathrm{R}_{1}=0.0246$ & $\mathrm{R}_{1}=0.0591$ & $\mathrm{R}_{1}=0.0534$ & $\mathrm{R}_{1}=0.0679$ & $\mathrm{R}_{1}=0.0551$ \\
\hline$[I>2 \sigma(I)]$ & $w_{2}=0.0574$ & $\mathrm{wR}_{2}=0.1273$ & $\mathrm{wR}_{2}=0.1339$ & $\mathrm{wR}_{2}=0.1686$ & $\mathrm{wR}_{2}=0.1298$ \\
\hline$R$ indices & $\mathrm{R}_{1}=0.0273$ & $\mathrm{R}_{1}=0.1370$ & $\mathrm{R}_{1}=0.0685$ & $\mathrm{R}_{1}=0.0943$ & $\mathrm{R}_{1}=0.1284$ \\
\hline (all data) & $w_{2}=0.0588$ & $\mathrm{wR}_{2}=0.1613$ & $\mathrm{wR}_{2}=0.1467$ & $\mathrm{wR}_{2}=0.1891$ & $w_{2}=0.1606$ \\
\hline
\end{tabular}




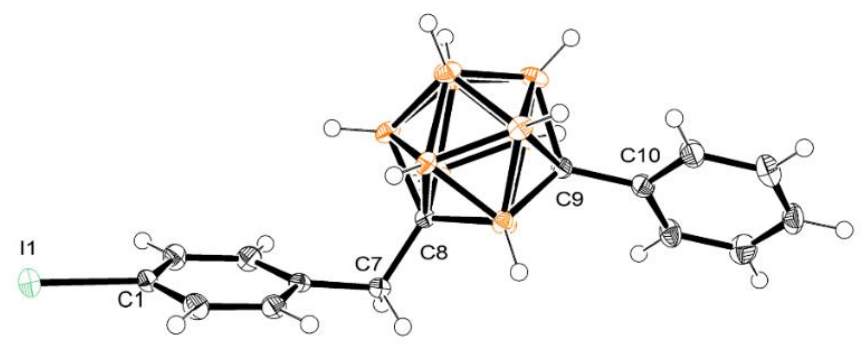

Figure 1. Solid-state structure for $\boldsymbol{m}$-Ph-CB. Thermal ellipsoids are drawn at $50 \%$ probability for every atom other than hydrogen. Selected bond lengths $[\AA]$ : C7-C8 1.530(5), C8-B1 1.710(5), C9-B1 1.708(5), C9-C10 1.511(4), I1-C1 2.086(3).

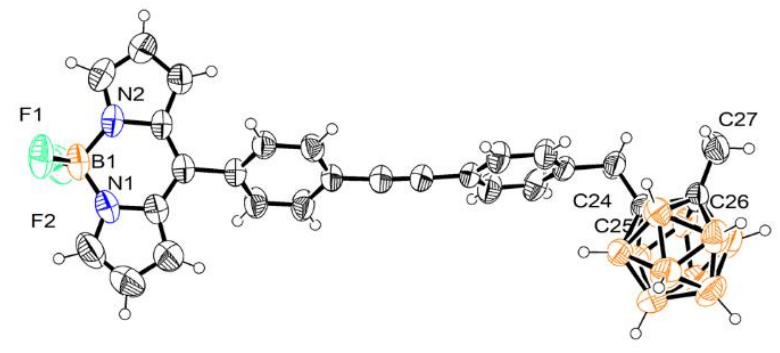

BODIPY-O-Me-CB
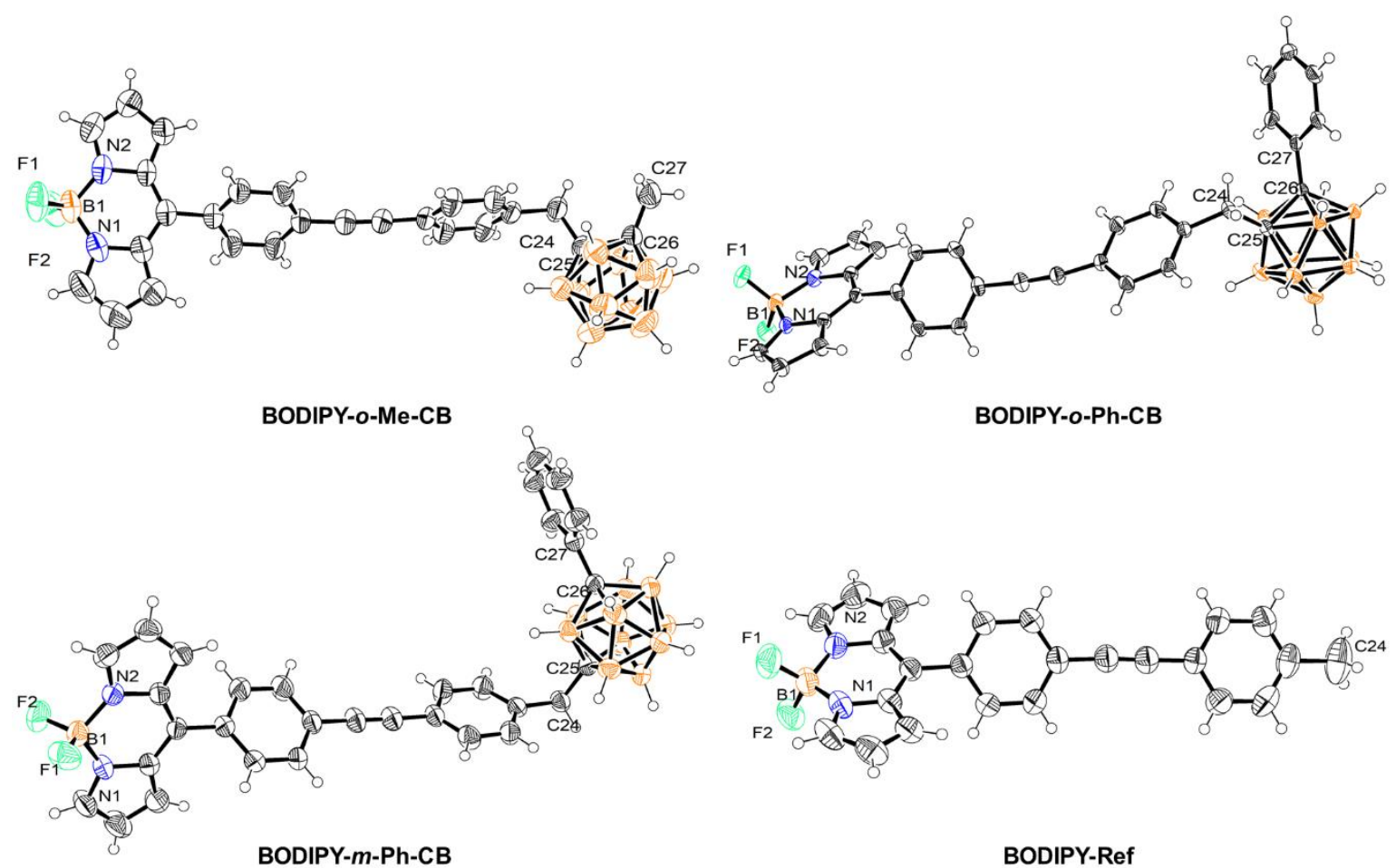

BODIPY-o-Ph-CB

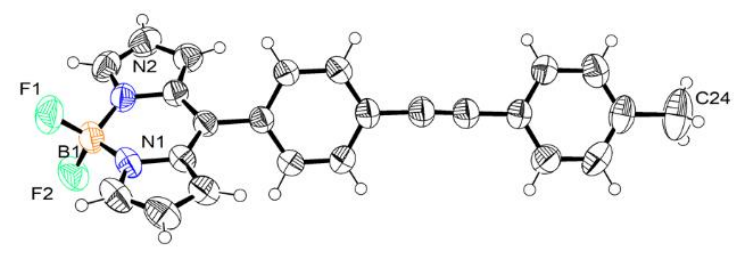

BODIPY-Ref

Figure 2. Solid-state structure for the target BODIPY derivatives with the thermal ellipsoids drawn at $50 \%$ probability for every atom other than hydrogen. Selected bond lengths $[\AA]$ and angles $\left[{ }^{\circ}\right]$ for BODIPY-o-Me-CB: B1-F1 1.375(3), B1-F2 1.382(3), B1-N1 1.532(4), B1-N2 1.537(4), C24-C25 1.532(3), C25-C26 1.674(3), C26-C27 1.517(4); F1-B1-F2 108.6(2), N1-B1-N2 106.4(2). For BODIPY-o-Ph-CB: B1-F1 1.3888(17), B1-F2 1.3779(18), B1-N1 1.5489(19), B1-N2 1.545(2), C24-C25 1.5299(18), C25-C26 1.7158(17), C26-C27 1.5011(18); F1-B1-F2 109.91(11), N1-B1-N2 105.62(10). For BODIPY-m-PhCB: B1-F1 1.386(3), B1-N1 1.527(4), B1-N2 1.536(4), B1-F2 1.372(3), C24-C25 1.530(3), C26-C27 1.508(3); F1-B1-F2 108.5(2), N1-B1-N2 106.7(2). For BODIPY-Ref: B1-F1 1.380(2), B1-F2 1.385(2), B1-N1 1.531(3), B1-N2 1.542(3); F1-B1-F2 108.29(15), N1-B1N2 106.18(14). For clarity, only one of the crystallographically independent molecules is presented for BODIPY-o-Me-CB. 
At this point, two crystal structures deserve further attention. As mentioned earlier, both BODIPY-o-Ph-CB and BODIPY-m-Ph-CB differing only on the position of the annular $\mathrm{C}_{\mathrm{c}}$ atoms within the dicarbaborane cluster, crystallized with disordered $n$-hexane molecules in a BODIPY/n-hexane 2/1 ratio. Nonetheless, their self-assemblies are considerably divergent, as markedly different crystallographic environments for the $n$-hexane molecules can be observed. As depicted in Figure 3, for BODIPY-o-Ph-CB the solvent molecules are confined within supramolecular pores formed by the antiparallel head-to-tail arrangement of pairs of fluorophores, spreading through the crystallographic $a$ axis. Contrastingly, for BODIPY-mPh-CB, the $n$-hexane molecules are very closely surrounded by fluorophore molecules. Importantly, in the ortho-isomer no close contacts are observed for the solvent molecules, whereas in the meta- one, 12 solvent-fluorophore short contacts (less than the sum of van der Waals radii) were found. This suggests that in the first case the $n$-hexane molecules move freely throughout the supramolecular channels, whilst in the latter one the solvent molecules are densely trapped within the crystal lattice, resulting in these supramolecular interactions. 


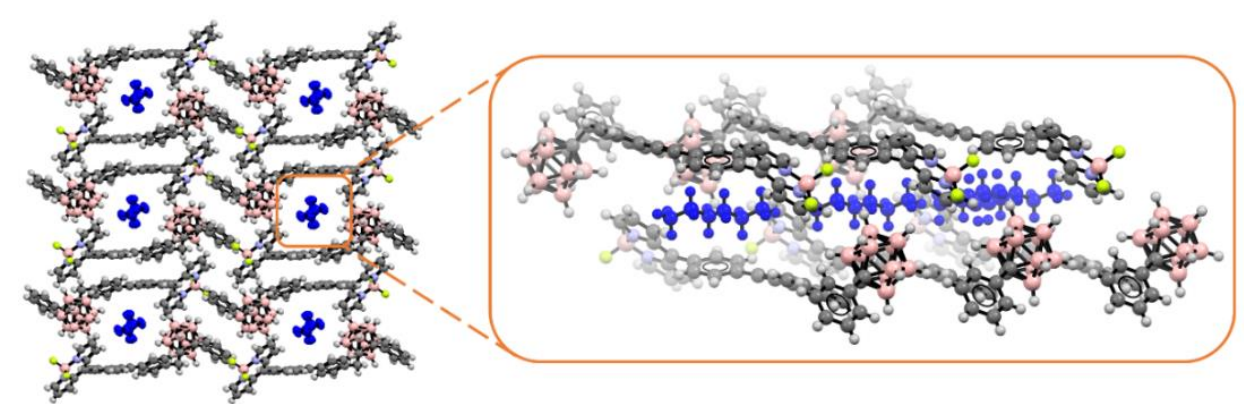

(a)

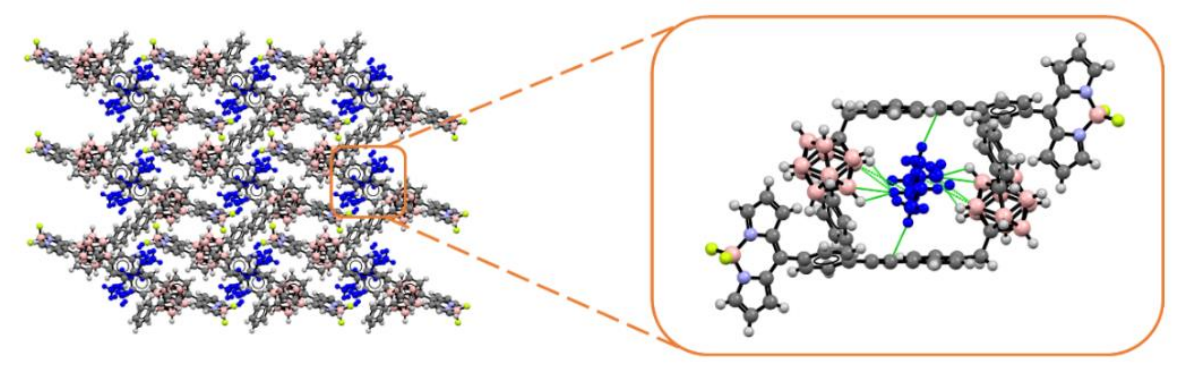

(b)

Figure 3. Crystallographic projections for (a) BODIPY-o-Ph-CB and (b) BODIPY-m-PhCB along the crystallographic $a$ and $b$ axes, respectively. Disordered $n$-hexane molecules are shown in blue.

In order to provide theoretical insights to support these observations, the difference in the solvation of the different species may tentatively be related to the DFT computation of the $\Delta \mathrm{G}^{\circ}$ (Gibbs free energies), that is associated to the following reaction:

$$
\text { BODIPY + hexane } \rightarrow \text { BODIPY : hexane }
$$

It is important to point out that this approach is based on a single hexane-BODIPY interaction (one explicit hexane along with a polarizable continuum model simulation for hexane). Therefore, it cannot be fully relevant to establish the complete behavior of the different isomers in the presence of solvent. Therefore, it must be used with care. The optimized geometries for both BODIPY-o-Ph-CB - hexane and BODIPY-m-Ph-CB - 
hexane interacting species are shown in Figure 4. Both starting models were built assuming that the molecules of solvent closest to the BODIPY-carboranyl dyads, in the solid state (present X-ray data), can account for most of the solvation interaction. Under such assumption $\Delta \mathrm{G}^{\circ}$ is equal to $+6.74 \mathrm{kcal} \mathrm{mol}^{-1}$ and $+2.42 \mathrm{kcal} \mathrm{mol}^{-1}$, for BODIPY-o-Ph-CB and BODIPY-m-Ph-CB, respectively. Therefore, the affinity for hexane appears clearly reduced in the case of the ortho isomer, in agreement with the X-ray structures.

An additional computational insight on the relative polarity of BODIPY-o-Ph-CB and BODIPY $-\boldsymbol{m}-\mathbf{P h}-\mathbf{C B}$, and hence their affinity to hexane is available by DFT. The computed dipole moments are equal to $8.22 \mathrm{D}$ and 4.86 D for BODIPY-o-Ph-CB and BODIPY-mPh-CB, respectively. These values confirm that the solvation in non-polar medium (hexane) is less favorable for the more polar BODIPY-o-Ph-CB species.

As discussed in detail later, these solid-state observations correlate well with the higher partition coefficients $(\log P$ ) values observed for BODIPY-m-Ph-CB compared to BODIPY-o-Ph-CB. Although formally, a direct comparison is not possible as the SXRD experiments and $\log P$ measurements are performed in different phases, it is not surprising to find out that the more lipophilic isomer BODIPY-m-Ph-CB interacts with non-polar $n$ hexane molecules, while for BODIPY-o-Ph-CB the $n$-hexane molecules remain isolated from the clusters. 

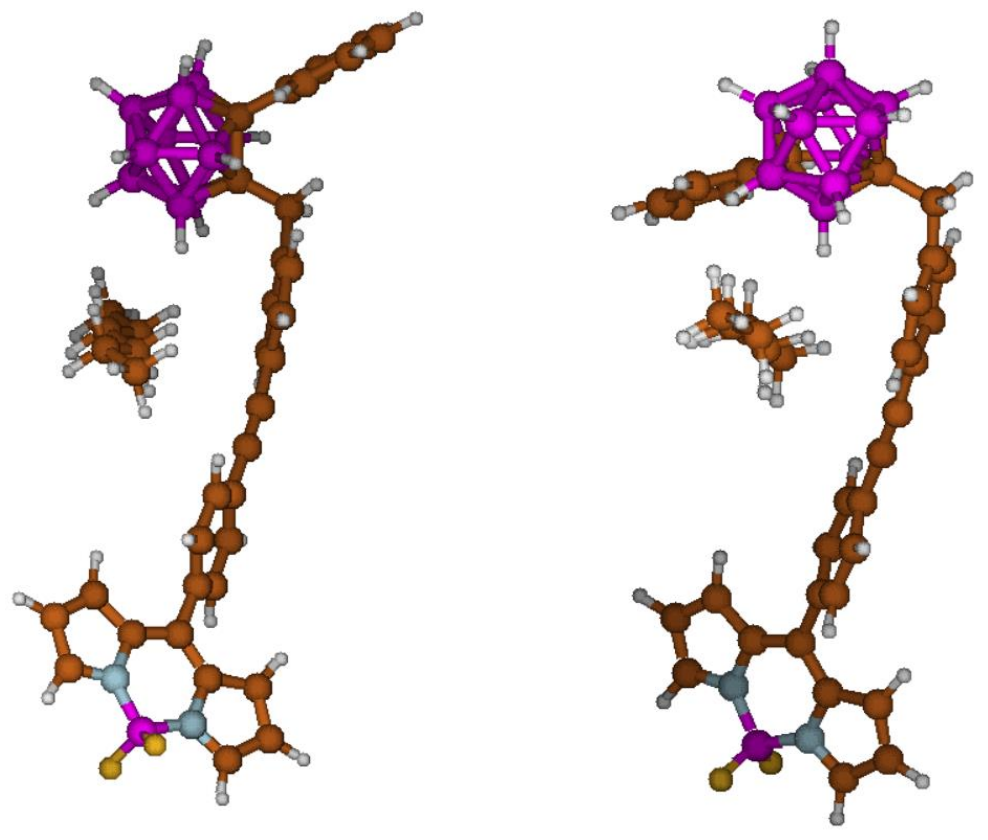

Figure 4. Computed geometries for BODIPY-o-Ph-CB (left) and BODIPY-m-Ph-CB (right) with one molecule of hexane.

\section{Photophysical Properties and TD-DFT Computations}

The photophysical properties of the target compounds were analysed by means of UV-Vis and fluorescence spectroscopies. Figure 5 shows the absorption and emission spectra for these fluorophores and Table 2 contains a summary of their experimental and computed photophysical properties. From Figure 5 it might be observed that the shape and energies associated to the electronic transitions remain practically unaltered regardless the substituent at the $\mathrm{C}_{\mathrm{c}}(\mathrm{Me}$ or $\mathrm{Ph})$ or the cluster isomer, when compared with the BODIPY-Ref. Only some differences in the extinction coefficients and fluorescence intensities were appreciated (Table 2). Both computation and experimental data match well with the observation of three local absorption maxima located around $500 \mathrm{~nm}, 380 \mathrm{~nm}$, and $280 \mathrm{~nm}$, which are readily 
attributed to transitions $1 \rightarrow 2,1 \rightarrow 3$, and $1 \rightarrow 7$, respectively. These closely related transitions involve the dominant contribution of HOMO $\rightarrow$ LUMO, HOMO-1 $\rightarrow$ LUMO, and HOMO- $1 \rightarrow$ LUMO+1 orbitals for transitions $1 \rightarrow 2,1 \rightarrow 3$, and $1 \rightarrow 7$, respectively. These sets of orbitals are shown in Figure 6, with their related energies. Regarding the electronic spectra, the contribution of the carboranyl cluster fragments appears negligible in all of them, leading to the expectations that the four BODIPY derivatives exhibit similar UVVis spectra. The wavelength of the emission maxima for all the compounds is centred at $\lambda_{\mathrm{em}}$ $=519 \mathrm{~nm}$ (Figure 5) $\left(\lambda_{\mathrm{exc}}=450 \mathrm{~nm}\right)$, regardless of the type of carboranyl group introduced, suggesting that there is not an important electronic communication between the BODIPY and the carborane cage. Moreover, the fluorescence quantum yields $\left(\Phi_{\mathrm{f}}\right)$ of $o$-carboranylBODIPY dyads are two-fold the $\Phi_{\mathrm{f}}$ of the non-substituted BODIPY-Ref, whereas a similar value is obtained for the $m$-carborane derivative, indicating that linking the cluster to the BODIPY produces an enhancement of the fluorescence efficiency of the fluorophores (Table 2). Due to the solution-state photophysical behaviour described above, these compounds were explored as fluorophores for in vitro imaging by confocal microscopy.

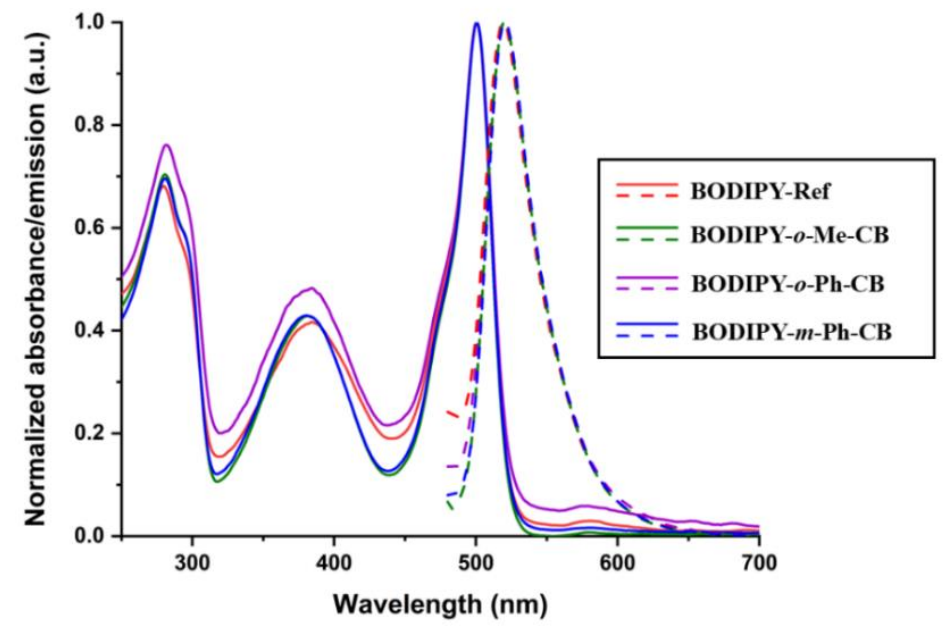

Figure 5. Normalized absorption (solid lines) and emission (dashed lines) spectra in ethanol for the target BODIPY derivatives. 
Table 2. Experimental and computed UV-Vis data and relative fluorescence quantum yields $\left(\Phi_{\mathrm{f}}\right.$ for the target BODIPY derivatives. Both computed and experimental values were measured/computed in ethanol.

\begin{tabular}{|c|c|c|c|c|c|c|c|c|}
\hline & & UV-Vis & & & TD-DFT & & $\lambda_{\mathrm{em}}$ & \\
\hline & $\lambda_{\max }$ & n) $\left[\varepsilon\left(\mathrm{M}^{-}\right.\right.$ & $\left.\left.\mathrm{m}^{-1}\right)\right]$ & & ax $(\mathrm{nm})[$ & & (nm) & \\
\hline $\begin{array}{l}\text { BODIPY- } \\
\text { Ref }\end{array}$ & $\begin{array}{c}280 \\
{[94309]}\end{array}$ & $\begin{array}{c}381 \\
{[35036]}\end{array}$ & $\begin{array}{c}501 \\
{[137908]}\end{array}$ & $\begin{array}{c}275 \\
{[0.770]}\end{array}$ & $\begin{array}{c}374 \\
{[0.792]}\end{array}$ & $\begin{array}{c}425 \\
{[0.510]}\end{array}$ & 519 & 0.0068 \\
\hline $\begin{array}{l}\text { BODIPY- } \\
o-M e-C B\end{array}$ & $\begin{array}{c}280 \\
{[127502]}\end{array}$ & $\begin{array}{c}381 \\
{[59536]}\end{array}$ & $\begin{array}{c}501 \\
{[178213]}\end{array}$ & $\begin{array}{c}275 \\
{[0.870]}\end{array}$ & $\begin{array}{c}367 \\
{[0.886]}\end{array}$ & $\begin{array}{c}426 \\
{[0.505]}\end{array}$ & 520 & 0.0108 \\
\hline $\begin{array}{l}\text { BODIPY- } \\
o-P h-C B\end{array}$ & $\begin{array}{c}280 \\
{[53213]}\end{array}$ & $\begin{array}{c}381 \\
{[79293]}\end{array}$ & $\begin{array}{c}501 \\
{[69151]}\end{array}$ & $\begin{array}{c}275 \\
{[0.829]}\end{array}$ & $\begin{array}{c}367 \\
{[0.884]}\end{array}$ & $\begin{array}{c}426 \\
{[0.505]}\end{array}$ & 520 & 0.0120 \\
\hline $\begin{array}{l}\text { BODIPY- } \\
m \text {-Ph-CB }\end{array}$ & $\begin{array}{c}280 \\
{[114067]}\end{array}$ & $\begin{array}{c}381 \\
{[71390]}\end{array}$ & $\begin{array}{c}501 \\
{[163988]}\end{array}$ & $\begin{array}{c}275 \\
{[0.839]}\end{array}$ & $\begin{array}{c}368 \\
{[0.876]}\end{array}$ & $\begin{array}{c}426 \\
{[0.502]}\end{array}$ & 521 & 0.0060 \\
\hline
\end{tabular}

${ }^{a}$ Obtained by irradiation at $\lambda=450 \mathrm{~nm}$, using Rhodamine B as standard with $\Phi_{\mathrm{f}}=0.5$ in ethanol. ${ }^{[24]}$

\section{Cellular Uptake and Intracellular Localization}

The fluorescence properties of all the dyads allow us to assess their subcellular distribution in live HeLa cells cultures, at different concentrations, by confocal microscopy at the green $\left(\lambda_{\mathrm{exc}}=486 \mathrm{~nm}, \lambda_{\mathrm{em}}=500 \mathrm{~nm}\right)$ and $\operatorname{red}\left(\lambda_{\mathrm{exc}}=535 \mathrm{~nm}, \lambda_{\mathrm{em}}=610 \mathrm{~nm}\right)$ channel setups (Fig. 7, S17 and S18); this is because in confocal microscopy-spectrally resolved studies, the fluorescence spectral bands of many fluorescence localizers can be strongly widespread in vitro conditions. In fact, we observed fluorescence signal at higher wavelengths (up to 550 $\mathrm{nm}$ ), which spatially correlate with the stronger green channel. As shown in Figure 7a-b, BODIPY-Ref and BODIPY-m-Ph-CB showed the best permeability and localization characteristics in this cell line. On the contrary, the ortho-derivatives BODIPY-o-Me-CB and BODIPY-o-Ph-CB poorly translocate the cell membrane probably because their less lipophilic character strongly favoured aggregation in the cell surface. Nonetheless, by using a low-dose stimulation with the ortho-derivatives, a better intake was observed (Figure 7c- 
d). While BODIPY-o-Me-CB exhibited a cytosolic distribution with still subtle particle agglomeration (having no membrane affinity), BODIPY-o-Ph-CB shows a perinuclear membrane localization, although non-specific. Importantly, the meta-derivative BODIPYm-Ph-CB showed excellent fluorescence distribution features, where the plasma membrane was mostly localized in a wide range of fluorophore concentrations, from 10 to $40 \mu \mathrm{M}$, having almost no variation in such subcellular distribution. Bright-field images as well as comparison with commercial plasma membrane localizer using CellMask® is shown in the Supporting Information (Fig. S19). It is worth mentioning that BODIPY-Ref also exhibited interesting membrane permeability with a non-specific localization in the perinuclear zone. Further, this fluorophore was able to specifically localize apoptotic vesicles and cellular blebs during cell oxidative stress. ${ }^{[25]}$ The low-dose stimulus with $\mathrm{H}_{2} \mathrm{O}_{2}$ was used in order for the blebs to be well-contrasted under the green channel illumination, allowing a bright in-plane bleb visualization with clean green-emission on these membranes. 


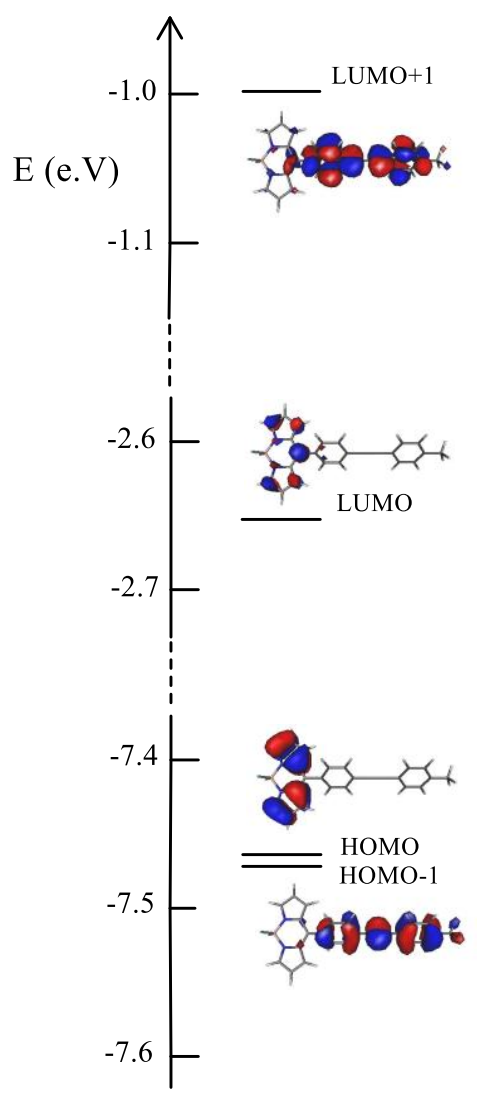

BODIPY-Ref
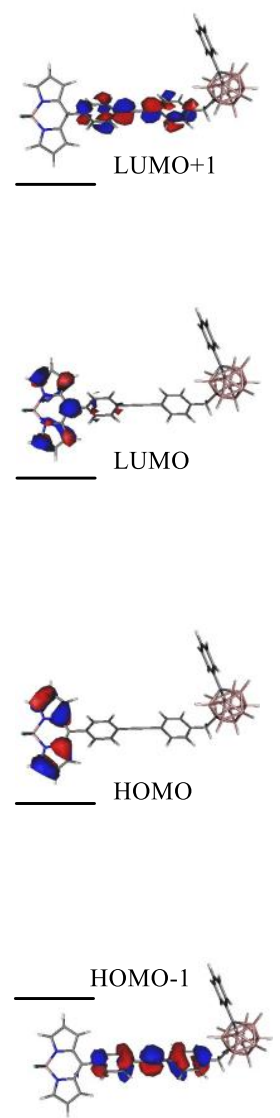

BODIPY-m-Ph-CB
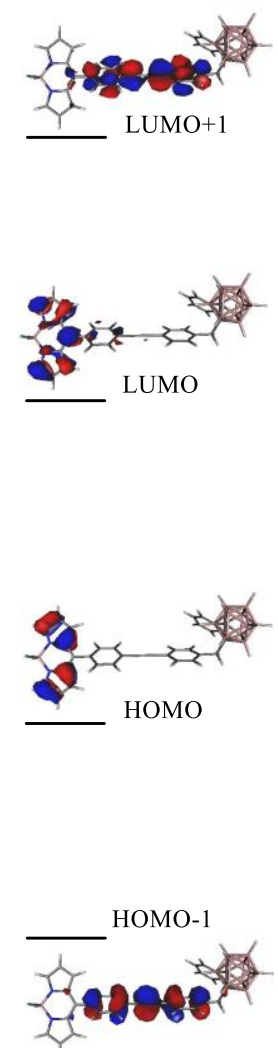

BODIPY-o-Ph-CB

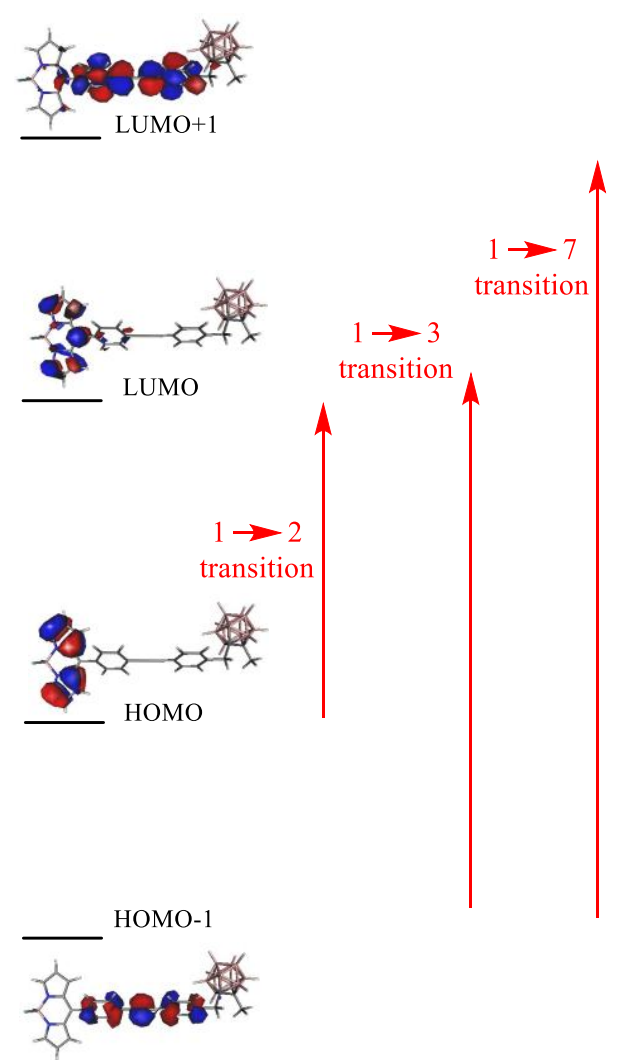

BODIPY-o-Me-CB

Figure 6. Dominant frontier orbitals involved in the three intense $1 \rightarrow 2,1 \rightarrow 3$, and $1 \rightarrow 7$ electronic transitions for BODIPY-Ref, BODIPY-m-Ph-CB, BODIPY-o-Ph-CB and BODIPY-o-Me-CB. 

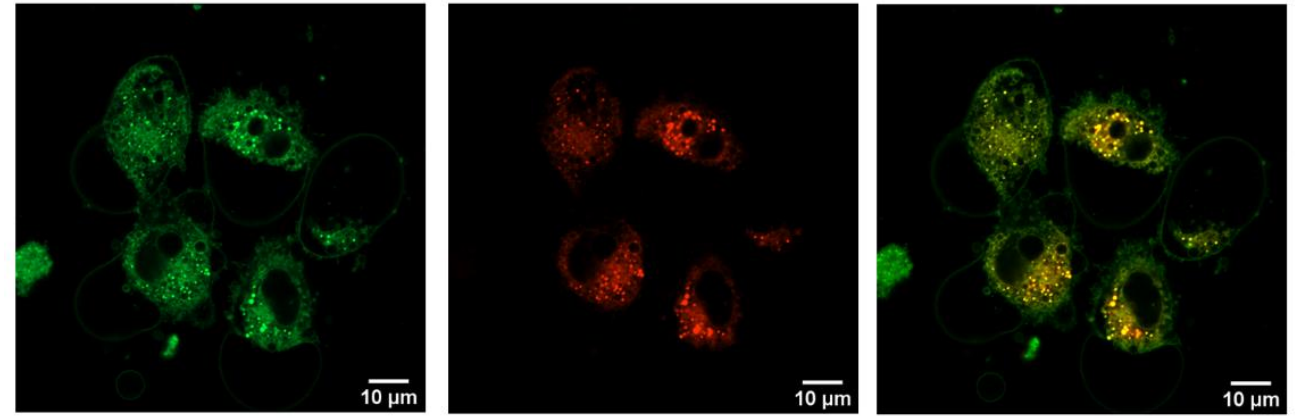

(a) BODIPY-Ref
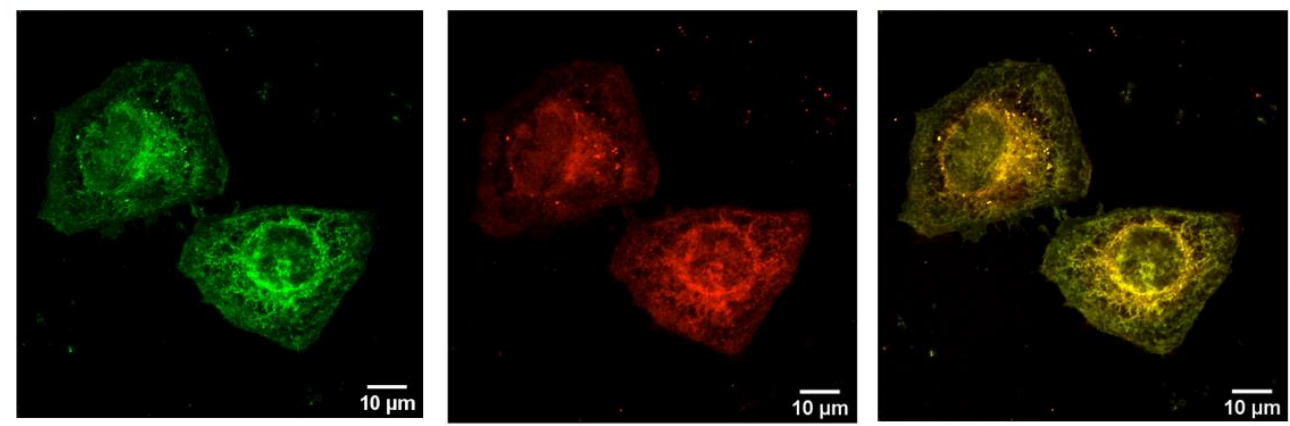

(b) BODIPY-m-Ph-CB
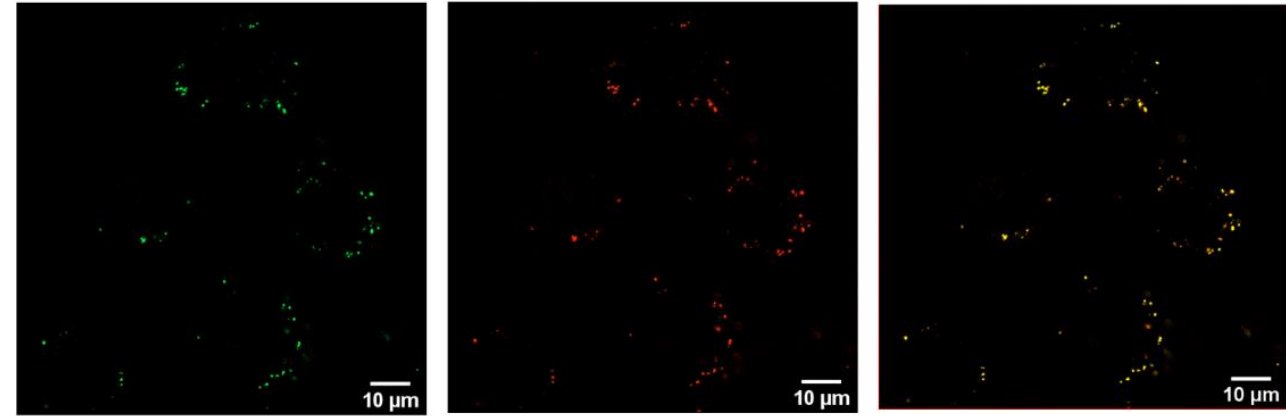

(c) BODIPY-o-Me-CB
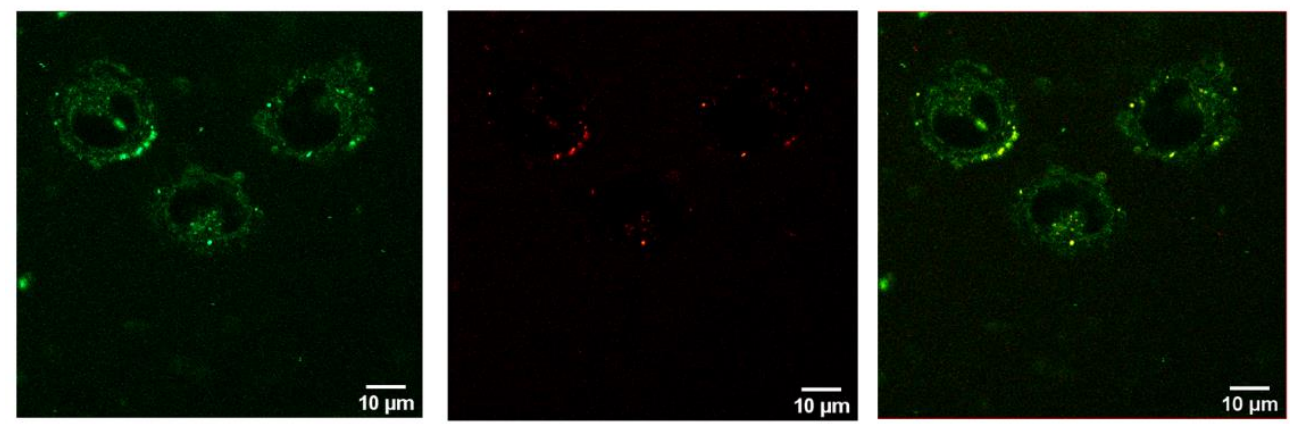

(d) BODIPY-o-Ph-CB

Figure 7. Confocal images of $10 \mu \mathrm{M}$ fluorophores in live HeLa cells after $30 \mathrm{~min}$ incubation.

Panels from left to right show the confocal green channel $\left(\lambda_{\mathrm{exc}}=486 \mathrm{~nm}, \lambda_{\mathrm{em}}=500 \mathrm{~nm}\right)$, red channel $\left(\lambda_{\mathrm{exc}}=535 \mathrm{~nm}, \lambda_{\mathrm{em}}=610 \mathrm{~nm}\right)$ and merged channels, respectively. 
At this point, we were motivated to investigate the origin of the divergent cell uptake efficiency and subcellular localization of these molecules, with the most striking differences arising from BODIPY-o-Ph-CB and BODIPY-m-Ph-CB. The molecular structure of these two compounds differ exclusively on the position of the endocyclic $\mathrm{C}_{\mathrm{c}}$ atoms, however they displayed completely different self-assemblies and fluorophore-cells interactions. Having in mind that the theoretical computations discussed earlier (vide supra) suggested a higher affinity of BODIPY-m-Ph-CB for non-polar molecules as $n$-hexane than its homologous ortho-isomer, we wondered if a difference in lipophilicity would provide an explanation for the divergent confocal microscopy results. Thus, as the lipophilic partition of some organic fluorophores is determined by their partition coefficients $(\log P),{ }^{[26]}$ we measured $\log P$ for these fluorophores (Table 3, Figure S20). Those molecules showing the best cell internalization also possessed the higher $\log P$ values, which correlate with a higher lipophilicity of BODIPY-Ref, BODIPY-m-Ph-CB and consequently a better interaction with the cell membranes. To gain further insight on these observations, we determined the van der Waals volume of these molecules and computed by DFT their static molecular dipoles. These two parameters could help us to rationalize the differences in $\log P$ and consequently in the internalization of the fluorophores into the cells. Both the molecular volume and the polarity of a molecule have long been recognized as critical factors determining its permeability. ${ }^{[27]}$ Although a correlation between $\log P$ and the size/volume of the molecules is absent, a negative proportional relationship of $\log P$ and the dipole moment appears to be present, correlating low polarities with higher $\log P$ values. Although this correlation provides a satisfactory explanation for the marked differences observed in the cell intake of fluorophores, further studies would be needed to correlate a larger interval of $\log P$ values and dipolar moments with the cell income of carboranyl derivatives. In this 
manner, the straightforward DFT computation of static dipole moments could eventually guide the design of fluorescent carboranyl derivatives with potential theragnostic applications.

Table 3. Partition coefficients $(\log P)$, dipolar moments $(\mu)$ and van der Waals volumes (Vvdw).

\begin{tabular}{lccc}
\hline & $\log \boldsymbol{P}^{\mathrm{a}}$ & $\boldsymbol{\mu}(\mathrm{D})^{\mathrm{b}}$ & ${\text { Vvdw }\left(\AA^{3} / \text { molecule }^{\mathrm{c}}\right.}^{\mathrm{c}}$ \\
\hline BODIPY-Ref & 0.324 & 8.29 & 950.97 \\
BODIPY-o-Me-CB & -0.166 & 10.07 & 1491.71 \\
BODIPY-o-Ph-CB & -0.211 & 8.22 & 1595.85 \\
BODIPY- $\boldsymbol{m}$-Ph-CB & 0.677 & 4.86 & 1589.56
\end{tabular}

${ }^{\mathrm{a}} \log P$ values were calculated using a octanol:water partitioning protocol. ${ }^{[28] \mathrm{b}}$ Computed at the M062X/6-31G(d,p) level of theory. ${ }^{c}$ Computed from the crystal structures using CSD-Materials. ${ }^{[2]}$

As a final remark, we would like to stress the significance of these results, as they provide an explanation for the specific and recurrent observation that diverse fluorophores bearing meta-carboranyl derivatives show better cell incomes than those of their orthocounterparts. ${ }^{[19 \mathrm{~g}]}$ Furthermore, the high lipophilicity of meta-isomers correlates well with their subcellular distributions, as these species generally localize in lipophilic membranous organelles. The understanding of the reasons behind this specific behaviour paves the way for designing new and better fluorescent carboranes for in vitro cell imaging.

\section{CONCLUSIONS}

The cell uptake efficiency and subcellular localization of a set of boron-dipyrromethene difluoride (BODIPY) dyes decorated with $\mathrm{C}_{\mathrm{c}}$-substituted carboranyl derivatives were investigated by confocal microscopy on living HeLa cells. They exhibited markedly 
divergent behaviours depending on the cluster isomer linked to the BODIPY core, whereas not great alterations with the substituents at $\mathrm{C}_{\mathrm{c}}$ was observed. A rationale for these differences was provided from a detailed structural and physicochemical characterization of these clusters, supported by a combination of experimental measurements and theoretical DFT computations. Altogether, our results show that the differences in cell income and subcellular distribution of the fluorophores originate from an important variation in their static dipole moments and partition coefficients, which modulates the ability of these molecules to interact with the lipophilic microenvironments in cells. It can be highlighted that these properties are indeed related to the type of cluster isomer linked to the BODIPY, being the $m$-carborane derivatives better internalized than their ortho- analogues. This evidence provides a molecular design strategy for improving the prospective applications of BODIPY-carboranyl dyads as potential fluorescence imaging agents and boron carriers for BNCT.

\section{EXPERIMENTAL}

\section{General Experimental Considerations}

Materials. All starting materials were purchased from Sigma-Aldrich and used without further purification. Solvents were purified by distillation over appropriate drying agents. Starting materials, BODIPY 1, $\boldsymbol{o}$-Me-CB, $\boldsymbol{o}$-Ph-CB and $\boldsymbol{m}$-Ph-CB were obtained following modified literature procedures $;{ }^{[5,30]}$ spectroscopic data is in good agreement.

Instrumentation. NMR spectra were recorded on Jeol ECA 500, Varian MR-400 and Bruker ARX 300 spectrometers using deuterated solvents; chemical shifts for ${ }^{1} \mathrm{H}$ and ${ }^{13} \mathrm{C}$ NMR data are relative to the residual nondeuterated solvent signal, fixed at $\delta=7.26 \mathrm{ppm}$ for ${ }^{1} \mathrm{H}-\mathrm{NMR}$ 
and $\delta=77.00 \mathrm{ppm}$ for ${ }^{13} \mathrm{C}$-NMR. Infrared spectra were registered on a FT-IR Varian ATR spectrometer. HRMS data was acquired using an Agilent G1969A MS TOF spectrometer.

\section{Synthesis of the Target BODIPY Derivatives.}

General Sonogashira Cross-Coupling procedure. To a round-bottom flask filled with BODIPY 1 ( $1 \mathrm{mmol}), \mathrm{Pd}\left(\mathrm{PPh}_{3}\right)_{2} \mathrm{Cl}_{2}(0.05 \mathrm{mmol}), \mathrm{CuI}(0.1 \mathrm{mmol})$ and a carboranyl benzyl iodide (o-Me-CB, $\boldsymbol{o}$-Ph-CB, $\boldsymbol{m}$-Ph-CB) or 4-iodotoluene (1 mmol) as coupling partner, were added THF $(30 \mathrm{~mL})$ and triethylamine $(30 \mathrm{~mL})$. The mixture was magnetically stirred overnight at room temperature, heated to reflux for 2 hours and evaporated under reduced pressure, the resulting residue was dissolved in methylene chloride $(100 \mathrm{~mL})$, washed with saturated ammonium chloride $(3 \times 40 \mathrm{~mL})$, dried over anhydrous sodium sulfate and purified through a chromatographic column packed with silica gel and eluted with hexane/acetone mixtures.

BODIPY-o-Me-CB. Red solid. Yield: $56 \%$. ${ }^{1} \mathrm{H}-\mathrm{NMR}\left(\mathrm{CDCl}_{3}, 400 \mathrm{MHz}\right) \delta 7.96$ (s, 2H, H1), $7.68(\mathrm{~d}, J=8.2 \mathrm{~Hz}, 2 \mathrm{H}, \mathrm{H}-8), 7.61-7.48(\mathrm{~m}, 4 \mathrm{H}, \mathrm{H}-7, \mathrm{H}-13), 7.22(\mathrm{~d}, J=8.1 \mathrm{~Hz}, 2 \mathrm{H}$, H-14), 6.95 (d, $J=4.1 \mathrm{~Hz}, 2 \mathrm{H}, \mathrm{H}-3), 6.57$ (d, $J=2.9 \mathrm{~Hz}, 2 \mathrm{H}, \mathrm{H}-2), 3.49$ (s, 2H, H-16), 2.18 (s, 3H, H-19), $2.64-1.89$ (m, 10H, B-H). ${ }^{13}$ C-NMR $\left(\mathrm{CDCl}_{3}, 100 \mathrm{MHz}\right) \delta 146.34(\mathrm{C}-5)$, 144.35 (C-1), 135.59 (C-15), 134.69 (C-4), 133.60 (C-9), 131.91 (C-13), 131.59 (C-8), 131.39 (C-3), 130.57 (C-7), 130.47 (C-14), 125.90 (C-6), 122.56 (C-12), 118.74 (C-2), 91.48 (C-11), 89.15 (C-10), 77.20 (C-18), 74.79 (C-17), 41.04 (C-16), 23.71 (C-19). ${ }^{11}$ B-NMR $\left(\mathrm{CDCl}_{3}, 128 \mathrm{MHz}\right) \delta-0.69\left(\mathrm{t}, J=28.8 \mathrm{~Hz}, 1 \mathrm{~B}, \mathrm{BF}_{2}\right),-5.61(\mathrm{~d}, J=270.5 \mathrm{~Hz}, 4 \mathrm{~B}, \mathrm{BH}),-9.13$

$--12.58(\mathrm{~m}, 6 \mathrm{~B}, \mathrm{BH}) .{ }^{19} \mathbf{F}-\mathrm{NMR}\left(\mathrm{CDCl}_{3}, 376 \mathrm{MHz}\right) \delta-144.89(\mathrm{q}, J=28.7 \mathrm{~Hz}) . \mathbf{H R M S}$ (ESI- 
TOF ${ }^{+}$) m/z: $\left[\mathrm{M}^{+}-\mathrm{F}\right]^{+}$Observed: 521.3356. Anal. calcd. for $\mathrm{C}_{27} \mathrm{H}_{29} \mathrm{~B}_{11} \mathrm{~N}_{2} \mathrm{~F}$ : 521.3338. Error: $3.45 \mathrm{ppm}$.

BODIPY-o-Ph-CB. Red solid. Yield: $81 \%$. ${ }^{\mathbf{H}} \mathrm{H}-\mathrm{NMR}\left(\mathrm{CDCl}_{3}, 400 \mathrm{MHz}\right) \delta 7.96$ (s, 2H, H1), $7.75-7.70$ (m, 2H, H-20), $7.68-7.65$ (m, 2H, H-8), 7.57 (dt, J=8.2, 1.5 Hz, 2H, H-7), $7.55-7.52$ (m, 1H, H-22), $7.50-7.47$ (m, 2H, H-21), 7.44 (dt, J = 8.5, 2.0 Hz, 2H, H-13), $6.95(\mathrm{~d}, J=4.2 \mathrm{~Hz}, 2 \mathrm{H}, \mathrm{H}-3), 6.85(\mathrm{~d}, J=8.3 \mathrm{~Hz}, 2 \mathrm{H}, \mathrm{H}-14), 6.58-6.55$ (m, 2H, H-2), 3.12 (s, 2H, H-16), 2.96 - 1.95 (m, 10H, BH). ${ }^{13}$ C-NMR $\left(\mathrm{CDCl}_{3}, 100 \mathrm{MHz}\right) \delta 146.35(\mathrm{C}-5)$, 144.34 (C-1), 135.84 (C-15), 134.71 (C-4), 133.56 (C-9), 131.67 (C-13), 131.56 (C-8), 131.48 (C-20), 131.37 (C-3), 130.95 (C-22), 130.70 (C-19), 130.55 (C-7), 130.19 (C-14), 129.11 (C-21), 125.95 (C-6), 122.30 (C-12), 118.70 (C-2), 91.59 (C-11), 89.01 (C-10), 83.70 (C-18), 81.45 (C-17), 40.78 (C-16). ${ }^{11} \mathbf{B}-\mathbf{N M R}\left(\mathrm{CDCl}_{3}, 128 \mathrm{MHz}\right) \delta-0.69(\mathrm{t}, J=28.8 \mathrm{~Hz}$ 1B, $\left.\mathrm{BF}_{2}\right),-4.29$ (br s, 2B, BH), -8.99--15.94 (m, 8B, BH). ${ }^{19} \mathbf{F}-\mathbf{N M R}\left(\mathrm{CDCl}_{3}, 376 \mathrm{MHz}\right) \delta$ 144.90 (q, $J=28.9 \mathrm{~Hz})$. HRMS (ESI-TOF $\left.{ }^{+}\right) m / z:\left[\mathrm{M}^{+}-\mathrm{F}\right]^{+}$Observed: 583.3519. Anal. calcd. for $\mathrm{C}_{32} \mathrm{H}_{31} \mathrm{~B}_{11} \mathrm{~N}_{2} \mathrm{~F}$ : 583.3495. Error: $4.11 \mathrm{ppm}$.

BODIPY-m-Ph-CB. Orange solid. Yield: $61 \% .{ }^{1} \mathbf{H}-\mathbf{N M R}\left(\mathrm{CDCl}_{3}, 400 \mathrm{MHz}\right) \delta 7.96(\mathrm{~s}, 2 \mathrm{H}$, H-1), 7.68 (d, $J=8.4$ Hz, 2H, H-8), 7.55 (dd, $J=15.4,8.3$ Hz, 4H, H-7, H-13), 7.36 (dd, $J=$ 8.2, 1.4 Hz, 2H, H-20), $7.29-7.23$ (m, 3H, H-21, H-22), 7.16 (d, J = 8.2 Hz, 2H, H-14), 6.95 (d, J = 4.1 Hz, 2H, H-3), $6.59-6.55$ (m, 2H, H-2), 3.30 (s, 2H, H-16), $2.68-1.74$ (m, 10H, B-H). ${ }^{13}$ C-NMR $\left(\mathrm{CDCl}_{3}, 100 \mathrm{MHz}\right) \delta 146.40(\mathrm{C}-5), 144.34$ (C-1), 137.59 (C-15), 135.14 (C19), 134.73 (C-4), 133.53 (C-9), 131.85 (C-13), 131.56 (C-8), 131.38 (C-3), 130.56 (C-7), 130.06 (C-14), 128.64 (C-22), 128.31 (C-21), 127.76 (C-20), 126.05 (C-6), 122.01 (C-12), 118.72 (C-2), 91.79 (C-11), 88.86 (C-10), 77.20 (C-18), 75.63 (C-17), 43.01 (C-16). ${ }^{11} \mathbf{B}-$ NMR $\left(\mathrm{CDCl}_{3}, 128 \mathrm{MHz}\right) \delta-0.69\left(\mathrm{t}, J=28.8 \mathrm{~Hz}, 1 \mathrm{~B}, \mathrm{BF}_{2}\right),-6.22--15.41(\mathrm{~m}, 10 \mathrm{~B}, \mathrm{BH})$. 
${ }^{19}$ F-NMR $\left(\mathrm{CDCl}_{3}, 376 \mathrm{MHz}\right) \delta-144.90(\mathrm{q}, J=28.8 \mathrm{~Hz}) . \mathbf{H R M S}\left(\mathrm{ESI}-\mathrm{TOF}^{+}\right) \mathrm{m} / z:\left[\mathrm{M}^{+}-\mathrm{F}\right]^{+}$ Observed: 583.3502. Anal. calcd. for $\mathrm{C}_{32} \mathrm{H}_{31} \mathrm{~B}_{11} \mathrm{~N}_{2} \mathrm{~F}$ : 583.3495. Error: $1.19 \mathrm{ppm}$.

BODIPY-Ref. Red solid. Yield: $45 \%$. ${ }^{1} \mathrm{H}-\mathrm{NMR}\left(\mathrm{CDCl}_{3}, 400 \mathrm{MHz}\right) \delta 7.95$ (br s, 2H, H-1), $7.67(\mathrm{~d}, J=8.1 \mathrm{~Hz}, 2 \mathrm{H}, \mathrm{H}-7), 7.56(\mathrm{~d}, J=8.1 \mathrm{~Hz}, 2 \mathrm{H}, \mathrm{H}-8), 7.47$ (d, $J=8.0 \mathrm{~Hz}, 2 \mathrm{H}, \mathrm{H}-13)$, $7.20(\mathrm{~d}, J=8.0 \mathrm{~Hz}, 2 \mathrm{H}, \mathrm{H}-14), 6.95(\mathrm{~d}, J=4.0 \mathrm{~Hz}, 2 \mathrm{H}, \mathrm{H}-3), 6.58-6.55(\mathrm{~m}, 2 \mathrm{H}, \mathrm{H}-2), 2.39$ (s, 3H, H-16). ${ }^{13} \mathrm{C}-\mathrm{NMR}\left(\mathrm{CDCl}_{3}, 100 \mathrm{MHz}\right) \delta 146.51$ (C-5), 144.24 (C-1), 139.10 (C-15), 134.70 (C-4), 133.21 (C-9), 131.63 (C-13), 131.47 (C-8), 131.39 (C-3), 130.53 (C-7), 129.24 (C-14), 126.42 (C-6), 119.54 (C-12), 118.67 (C-2), 92.56 (C-11), 87.73 (C-10), 21.55 (C16). ${ }^{19} \mathbf{F}-\mathbf{N M R}\left(\mathrm{CDCl}_{3}, 376 \mathrm{MHz}\right) \delta-144.86(\mathrm{q}, J=28.8 \mathrm{~Hz}) .{ }^{11} \mathbf{B}-\mathbf{N M R}\left(\mathrm{CDCl}_{3}, 128 \mathrm{MHz}\right)$ $\delta-0.68(\mathrm{t}, J=28.8 \mathrm{~Hz}) . \mathbf{H R M S}\left(\mathrm{ESI}-\mathrm{TOF}^{+}\right) \mathrm{m} / z:\left[\mathrm{M}^{+}+\mathrm{H}\right]^{+}$Observed: 383.1544. Anal. calcd. for $\mathrm{C}_{24} \mathrm{H}_{18} \mathrm{BF}_{2} \mathrm{~N}_{2}$ : 383.1531 . Error: $3.39 \mathrm{ppm}$.

Single X-Ray Diffraction studies. The intensity data were collected on Oxford Diffraction Gemini "A" (m-Ph-CB) and Bruker D8 Venture CMOS (BODIPY-Ref, BODIPY-o-MeCB, BODIPY-o-Ph-CB, BODIPY-m-Ph-CB) diffractometers equipped with CCD area detectors ( $\lambda_{\mathrm{MoK} \alpha}=0.71073 \mathrm{~A}^{\circ}$, monochromator: graphite) at $130 \mathrm{~K}$ and room temperature, respectively. The crystals were mounted on conventional MicroLoops. ${ }^{\mathrm{TM}}$ All heavier atoms were found by Fourier map difference and refined anisotropically. All reflection data set were corrected for Lorentz and polarization effects. The first structure solution was obtained using the SHELXS-2018 program and the SHELXL-2018 was applied for refinement and output data. $^{[31]}$ All software manipulations were performed through the ShelXle program. ${ }^{[32]}$ Mercury 3.7 and ORTEP-3 were used to prepare artwork representations. ${ }^{[33]}$ 
CCDC 1975442-1975446 contain the supplementary crystallographic data for this paper. These data can be obtained free of charge via https://summary.ccdc.cam.ac.uk/structuresummary-form (or from the Cambridge Crystallographic Data Centre, 12, Union Road, Cambridge CB2 1EZ, UK; fax: +44 1223 336033).

Steady State Spectroscopy. Absorption spectra were acquired in a $10 \mathrm{~mm}$ path-length quartz-cell Cary-50 (Varian) spectrophotometer with dual beam, Czerny-Turner monochromator, 190-1100 nm wavelength range, approximately $1.5 \mathrm{~nm}$ fixed spectral bandwidth, full spectrum Xe pulse lamp, dual Si diode detectors, quartz overcoated optics, scan rates up to $24000 \mathrm{~nm} / \mathrm{min}$, at room temperature $\left(20 \pm 1^{\circ} \mathrm{C}\right)$ under aerated conditions. Fluorescence experiments were measured on a FluoroMax spectrofluorometer from HORIBA Scientific with Vertically mounted, CW, 150 W Ozone-free xenon arc lamp. Emission: R928P photon counting PMT (185-850 nm) and reference photodiode for monitoring lamp output at room temperature $\left(20 \pm 1^{\circ} \mathrm{C}\right)$ under aerated conditions. All the photophysical measurements were performed on $1 \mathrm{mM}$ solutions of the analytes in ethanol.

Optical Microscopy. The microscopy images were taken using an inverted Zeiss LSM 880 microscope maintaining $5 \% \mathrm{CO}_{2}$ and $37^{\circ} \mathrm{C}$ during the experiments. HeLa cells were seeded in 8 well $\mu$-slides (iBidi, Germany) at a density of 20000 cells per well one day prior to experiments in MEM alpha with 10\% FBS. On treatment day, cells were washed once in MEM alpha with no FBS, and incubated with compounds at different concentrations, from 10 to $40 \mu \mathrm{M}$, for 30 minutes. Cells were then washed twice in MEM alpha with no FBS and imaged. 
Computational Methods. BODIPY-Ref, BODIPY-m-Ph-CB, BODIPY-o-Ph-CB and BODIPY-o-Me-CB were fully optimized at the M06-2X/6-31G* level, using the Gaussian09 program package ${ }^{[34]}$ within the framework of the Density Functional Theory (DFT). The computation were performed assuming the presence of ethanol as the solvent, which was modeled by the Polarizable Continuum Model (SCRF=PCM method). ${ }^{[35]}$ For the computations devoted to the interaction with hexane (Equation 1), no other solvent effect was taken into account than the presence of one molecule of hexane in the vicinity of the cluster. We selected the M06-2X hybrid functional following the previous report by Jacquemin, ${ }^{[36]}$ who recommends M06-2X as the most reasonable DFT method for molecules based on the BODIPY units. The optimized coordinates are provided in Supplementary Materials. The UV-vis spectra were computed at the M06-2X/6-311+G** level. ${ }^{[36]}$

\section{AUTHOR INFORMATION}

*E-mail: rosario@icmab.es

* E-mail: norberto.farfan@gmail.com

\section{Conflict of interest}

The authors declare no conflict of interest.

\section{ACKNOWLEDGEMENTS}

The work has been performed within the framework of the French-Mexican International Laboratory (LIA-LCMMC). Authors acknowledge support from PAPIIT (IN222819) and CONACyT. The work was supported by Spanish Ministerio de Economía y Competitividad, MINECO (CTQ2016-75150-R) and Generalitat de Catalunya (2017/SGR/1720). Doctoral 
scholarships were granted by CONACyT to P.L.-V (337958) and R. F.-C. (576635). We thank María E. Ochoa (CINVESTAV-IPN), Marco A. Leyva (CINVESTAV-IPN) and Flor R. Vega (FQ-UNAM) for NMR/HRMS experiments, SXRD experiments and technical support, correspondingly.

\section{ASSOCIATED CONTENT}

Supporting Information Available: Synthesis of the starting materials, ${ }^{1} \mathrm{H},{ }^{13} \mathrm{C}$ NMR and HRMS spectra, atomic coordinates for the four DFT-optimized BODIPY derivative, confocal images and plots of $\log P$.

\section{REFERENCES}

[1] a) R. N. Grimmes, Carboranes, Academic Press, Boston, 2016 b) M. Scholz and E. HeyHawkins, Chem. Rev. 2011, 111, 7035-7062; c) N. S. Hosmane, Boron Science: New Technologies and Applicatons, Taylor \& Francis, Bosa Roca, 2012.

[2] a) J. Cabrera-González, A. Ferrer-Ugalde, S. Bhattacharyya, M. Chaari, F. Teixidor, J. Gierschner and R. Núñez, J. Mater. Chem. C 2017, 5, 10211-10219; b) A. Ferrer-Ugalde, E. J. Juárez-Pérez, F. Teixidor, C. Viñas and R. Núñez, Chem. Eur. J. 2013, 19, 17021-17030;

c) R. Núñez, I. Romero, F. Teixidor and C. Viñas, Chem. Soc. Rev. 2016, 45, 5147-5173.

[3] a) Z. Chen and R. B. King, Chem. Rev. 2005, 105, 3613-3642; b) J. Poater, M. Solà, C. Viñas and F. Teixidor, Chem. Eur. J. 2013, 19, 4372-4372.

[4] a) J. Poater, M. Solà, C. Viñas and F. Teixidor, Angew. Chem. Int. Ed. 2014, 53, 1219112195; b) P. Stockmann, M. Gozzi, R. Kuhnert, M. B. Sárosi and E. Hey-Hawkins, Chem. Soc. Rev. 2019, 48, 3497-3512. 
[5] A. Ferrer-Ugalde, J. Cabrera-González, E. J. Juárez-Pérez, F. Teixidor, E. Pérez-

Inestrosa, J. M. Montenegro, R. Sillanpää, M. Haukka and R. Núñez, Dalton Trans. 2017, 46, 2091-2104.

[6] Y. Zhu and N. S. Hosmane, J. Organomet. Chem. 2017, 849-850, 286-292.

[7] a) R. Furue, T. Nishimoto, I. S. Park, J. Lee and T. Yasuda, Angew. Chem. Int. Ed. 2016, 55, 7171-7175; b) K.-R. Wee, Y.-J. Cho, S. Jeong, S. Kwon, J.-D. Lee, I.-H. Suh and S. O. Kang, J. Am. Chem. Soc. 2012, 134, 17982-17990; c) R. Núñez, M. Tarrés, A. Ferrer-Ugalde, F. F. de Biani and F. Teixidor, Chem. Rev. 2016, 116, 14307-14378.

[8] a) X.-Q. Li, C.-H. Wang, M.-Y. Zhang, H.-Y. Zou, N.-N. Ma and Y.-Q. Qiu, J. Organomet. Chem. 2014, 749, 327-334; b) J. Wang, W.-Y. Wang, X.-Y. Fang and Y.-Q. Qiu, J. Mol. Model. 2015, 21, 95.

[9] a) A. Saha, E. Oleshkevich, C. Vinas and F. Teixidor, Adv. Mater. 2017, 29, 1704238; b) E. A. Qian, A. I. Wixtrom, J. C. Axtell, A. Saebi, D. Jung, P. Rehak, Y. Han, E. H. Moully, D. Mosallaei, S. Chow, M. S. Messina, J. Y. Wang, A. T. Royappa, A. L. Rheingold, H. D. Maynard, P. Král and A. M. Spokoyny, Nat. Chem. 2017, 9, 333-340; c) L. Gan, A. Chidambaram, P. G. Fonquernie, M. E. Light, D. Choquesillo-Lazarte, H. Huang, E. Solano, J. Fraile, C. Viñas, F. Teixidor, J. A. R. Navarro, K. C. Stylianou and J. G. Planas, J. Am. Chem. Soc. 2020, 142, 8299-8311; d) F. Tan, A. López-Periago, M. E. Light, J. Cirera, E. Ruiz, A. Borrás, F. Teixidor, C. Viñas, C. Domingo and J. G. Planas, Adv. Mater. 2018, 30, 1800726.

[10] a) Boron-Based Compounds, John Wiley \& Sons Ltd, Chichester, UK, 2018 b) J. F. Valliant, K. J. Guenther, A. S. King, P. Morel, P. Schaffer, O. O. Sogbein and K. A. Stephenson, Coord. Chem. Rev. 2002, 232, 173-230; c) I. B. Sivaev and V. V. Bregadze, Eur. J. Inorg. Chem. 2009, 2009, 1433-1450; d) C. Gianpiero, D. Anis, R. Aikaterini, T. Eirini, V. S. Ioannis, F. G. Dimitrios and T. John, MedChemComm 2017, 8, 67-72; e) H. S. Ban and H. Nakamura, Chem. Rec. 2015, 15, 616-635; f) M. A. Soriano-Ursúa, B. C. Das and J. G. Trujillo-Ferrara, Expert Opin. Ther. Pat. 2014, 24, 485-500.

[11] F. Issa, M. Kassiou and L. M. Rendina, Chem. Rev. 2011, 111, 5701-5722.

[12] a) C. Viñas, R. Núñez, I. Bennour and F. Teixidor, Curr. Med. Chem. 2019, 26, 50365076; b) C. Viñas, Future Med. Chem. 2013, 5, 617-619; c) Z. J. Leśnikowski, J. Med. Chem. 2016, 59, 7738-7758; d) C. Viñas, Future Med. Chem. 2013, 5, 617-619. 
[13] a) R. F. Barth, P. Mi and W. Yang, Cancer Commun. 2018, 38, 35; b) S.-I. Miyatake, S. Kawabata, K. Yokoyama, T. Kuroiwa, H. Michiue, Y. Sakurai, H. Kumada, M. Suzuki, A. Maruhashi, M. Kirihata and K. Ono, J. Neuro-Oncol. 2009, 91, 199-206; c) J. Hiratsuka, N. Kamitani, R. Tanaka, E. Yoden, R. Tokiya, M. Suzuki, R. F. Barth and K. Ono, Cancer Commun. 2018, 38, 38; d) K. Hu, Z. Yang, L. Zhang, L. Xie, L. Wang, H. Xu, L. Josephson, S. H. Liang and M.-R. Zhang, Coord. Chem. Rev. 2020, 405, 213139; e) H. Nakamura and M. Kirihata in Neutron Capture Therapy, (Eds.: W. Sauerwein, A. Wittig, R. Moss, Y. Nakagawa), Springer, 2012, pp. 99-116; f) M. Sibrian-Vazquez and M. G. H. Vicente in Boron Tumor-Delivery for BNCT: Recent Developments and Perspectives, (Ed. N. S. Hosmane), Taylor \& Francis, Bosa Roca, 2012, pp. 209-242.

[14] a) F. Lerouge, C. Viñas, F. Teixidor, R. Núñez, A. Abreu, E. Xochitiotzi, R. Santillan and N. Farfán, Dalton Trans. 2007, 1898-1903; b) F. Lerouge, A. Ferrer-Ugalde, C. Viñas, F. Teixidor, R. Sillanpää, A. Abreu, E. Xochitiotzi, N. Farfán, R. Santillan and R. Núñez, Dalton Trans. 2011, 40, 7541-7550; c) J. Cabrera-González, C. Viñas, M. Haukka, S. Bhattacharyya, J. Gierschner and R. Núñez, Chem. Eur. J. 2016, 22, 13588-13598; d) J. Cabrera-González, E. Xochitiotzi-Flores, C. Viñas, F. Teixidor, H. García-Ortega, N. Farfán, R. Santillan, T. Parella and R. Núñez, Inorg. Chem. 2015, 54, 5021-5031; e) A. FerrerUgalde, A. González-Campo, C. Viñas, J. Rodríguez-Romero, R. Santillan, N. Farfán, R. Sillanpää, A. Sousa-Pedrares, R. Núñez and F. Teixidor, Chem. Eur. J. 2014, 20, 9940-9951; f) M. Chaari, J. Cabrera-González, Z. Kelemen, C. Viñas, A. Ferrer-Ugalde, D. ChoquesilloLazarte, A. Ben Salah, F. Teixidor and R. Núñez, J. Organomet. Chem. 2018, 865, 206-213. [15] a) J. L. Fauchère, K. Q. Do, P. Y. C. Jow and C. Hansch, Experientia 1980, 36, 12031204; b) K. Yamamoto and Y. Endo, Bioorg. Med. Chem. Lett. 2001, 11, 2389-2392.

[16] a) A. Bessette and G. S. Hanan, Chem. Soc. Rev. 2014, 43, 3342-3405; b) R. Ziessel, G. Ulrich and A. Harriman, New J. Chem. 2007, 31, 496-501.

[17] a) J. Bañuelos, Chem. Rec. 2016, 16, 335-348; b) G. Ulrich, R. Ziessel and A. Harriman, Angew. Chem. Int. Ed. 2008, 47, 1184-1201.

[18] T. Kowada, H. Maeda and K. Kikuchi, Chem. Soc. Rev. 2015, 44, 4953-4972.

[19] a) S. Xuan, N. Zhao, Z. Zhou, F. R. Fronczek and M. G. H. Vicente, J. Med. Chem. 2016, 59, 2109-2117; b) J. H. Gibbs, H. Wang, N. V. S. D. K. Bhupathiraju, F. R. Fronczek, K. M. Smith and M. G. H. Vicente, J. Organomet. Chem. 2015, 798, 209-213; c) I. Nar, A. 
Atsay, A. Buyruk, H. Pekbelgin Karaoğlu, A. K. Burat and E. Hamuryudan, New J. Chem. 2019, 43, 4471-4476; d) S.-Y. Kim, Y.-J. Cho, H.-J. Son, D. W. Cho and S. O. Kang, J. Phys. Chem. A 2018, 122, 3391-3397; e) E. Berksun, I. Nar, A. Atsay, İ. Özçeşmeci, A. Gelir and E. Hamuryudan, Inorg. Chem. Front. 2018, 5, 200-207; f) R. Ziessel, G. Ulrich, J. H. Olivier, T. Bura and A. Sutter, Chem. Commun. 2010, 46, 7978-7980; g) C. Bellomo, M. Chaari, J. Cabrera-González, M. Blangetti, C. Lombardi, A. Deagostino, C. Viñas, N. Gaztelumendi, C. Nogués, R. Nuñez and C. Prandi, Chem. Eur. J. 2018, 24, 15622-15630.

[20] M. Chaari, N. Gaztelumendi, J. Cabrera-González, P. Peixoto-Moledo, C. Viñas, E. Xochitiotzi-Flores, N. Farfán, A. Ben Salah, C. Nogués and R. Núñez, Bioconjugate Chem. 2018, 29, 1763-1773.

[21] a) M. Chaari, Z. Kelemen, D. Choquesillo-Lazarte, N. Gaztelumendi, F. Teixidor, C. Viñas, C. Nogués and R. Núñez, Biomater. Sci. 2019, 7, 5324-5337; b) M. Tarrés, E. Canetta, E. Paul, J. Forbes, K. Azzouni, C. Viñas, F. Teixidor and A. J. Harwood, Sci. Rep. 2015, 5, 7804.

[22] a) I. Moriguchi, Y. Kanada and K. Komatsu, Chem. Pharm. Bull. 1976, 24, 1799-1806;

b) K. N. Reddy and M. A. Locke, Water Air Soil Pollut. 1996, 86, 389-405.

[23] A. M. Spokoyny, C. W. Machan, D. J. Clingerman, M. S. Rosen, M. J. Wiester, R. D. Kennedy, C. L. Stern, A. A. Sarjeant and C. A. Mirkin, Nat. Chem. 2011, 3, 590-596.

[24] T. Karstens and K. Kobs, J. Phys. Chem. 1980, 84, 1871-1872.

[25] E. Palacios-Serrato, D. Araiza-Olivera and A. Jiménez-Sánchez, Anal. Chem. 2020, 92, 3888-3895.

[26] A. Jiménez-Sánchez, E. K. Lei and S. O. Kelley, Angew. Chem. Int. Ed. 2018, 57, 88918895.

[27] C. A. Lipinski, F. Lombardo, B. W. Dominy and P. J. Feeney, Adv. Drug Deliv. Rev. 2001, 46, 3-26.

[28] L. F. Yousif, K. M. Stewart, K. L. Horton and S. O. Kelley, ChemBioChem 2009, 10, 2081-2088.

[29] C. R. Groom, I. J. Bruno, M. P. Lightfoot and S. C. Ward, Acta Crystallogr. B 2016, 72, 171-179.

[30] M. Benstead, G. A. Rosser, A. Beeby, G. H. Mehl and R. W. Boyle, Photochem. Photobiol. Sci. 2011, 10, 992-999. 
[31] G. Sheldrick, Acta Crystallogr. A 2008, 64, 112-122.

[32] C. B. Hubschle, G. M. Sheldrick and B. Dittrich, J. Appl. Crystallogr. 2011, 44, 12811284.

[33] a) C. F. Macrae, P. R. Edgington, P. McCabe, E. Pidcock, G. P. Shields, R. Taylor, M. Towler and J. van de Streek, J. Appl. Crystallogr. 2006, 39, 453-457; b) L. Farrugia, J. Appl. Crystallogr. 1997, 30, 565.

[34] Gaussian 09, Revision D.01, M. J. Frisch, G. W. Trucks, H. B. Schlegel, G. E. Scuseria, M. A. Robb, J. R. Cheeseman, G. Scalmani, V. Barone, B. Mennucci, G. A. Petersson, H. Nakatsuji, M. Caricato, X. Li, H. P. Hratchian, A. F. Izmaylov, J. Bloino, G. Zheng, J. L. Sonnenberg, M. Hada, M. Ehara, K. Toyota, R. Fukuda, J. Hasegawa, M. Ishida, T. Nakajima, Y. Honda, O. Kitao, H. Nakai, T. Vreven, J. A. Montgomery, Jr., J. E. Peralta, F. Ogliaro, M. Bearpark, J. J. Heyd, E. Brothers, K. N. Kudin, V. N. Staroverov, R. Kobayashi, J. Normand, K. Raghavachari, A. Rendell, J. C. Burant, S. S. Iyengar, J. Tomasi, M. Cossi, N. Rega, J. M. Millam, M. Klene, J. E. Knox, J. B. Cross, V. Bakken, C. Adamo, J. Jaramillo, R. Gomperts, R. E. Stratmann, O. Yazyev, A. J. Austin, R. Cammi, C. Pomelli, J. W. Ochterski, R. L. Martin, K. Morokuma, V. G. Zakrzewski, G. A. Voth, P. Salvador, J. J. Dannenberg, S. Dapprich, A. D. Daniels, Ö. Farkas, J. B. Foresman, J. V. Ortiz, J. Cioslowski, and D. J. Fox, Gaussian, Inc., Wallingford CT, 2009.

[35] J. Tomasi, B. Mennucci and R. Cammi, Chem. Rev. 2005, 105, 2999-3094.

[36] A. Charaf-Eddin, B. Le Guennic and D. Jacquemin, $R S C A d v$. 2014, 4, 49449-49456. 